\title{
DEMOCRATIZAÇÃO DO CONTROLE DE CONSTITUCIONALIDADE: ANÁLISE DAS EMENDAS CONSTITUCIONAIS NO BRASIL PÓS-1988
}

\author{
Tese de Doutorado \\ Orientador: Professor Associado Dr. Rubens Beçak
}

UNIVERSIDADE DE SÃO PAULO

FACULDADE DE DIREITO

São Paulo - SP

2018 



\title{
JAIRO NÉIA LIMA
}

\section{DEMOCRATIZAÇÃO DO CONTROLE DE CONSTITUCIONALIDADE: ANÁLISE DAS EMENDAS CONSTITUCIONAIS NO BRASIL PÓS-1988}

\author{
Tese apresentada à Banca Examinadora do \\ Programa de Pós-Graduação em Direito, da \\ Faculdade de Direito da Universidade de São Paulo, \\ como exigência parcial para a obtenção do título de \\ Doutor em Direito, na área de concentração Direito \\ do Estado, sob orientação do Prof. Associado Dr. \\ Rubens Beçak.
}

UNIVERSIDADE DE SÃO PAULO

FACULDADE DE DIREITO

São Paulo - SP 
Catalogação da Publicação

Serviço de Biblioteca e Documentação

Faculdade de Direito da Universidade de São Paulo

Lima, Jairo Néia

DEMOCRATIZAÇÃO DO CONTROLE DE CONSTITUCIONALIDADE: ANÁLISE DAS EMENDAS CONSTITUCIONAIS NO BRASIL PÓS-1988 /

Jairo Néia Lima ; orientador Rubens Beçak -- São Paulo, 2018.

2018

Tese (Doutorado - Programa de Pós-Graduação em Direito do Estado) Faculdade de Direito, Universidade de São Paulo, 2018.

1. Emenda constitucional. 2. Constitucionalidade das leis. 3. Maioria politica. I. Beçak, Rubens, orient. II. Título. 
Jairo Néia Lima. Democratização do controle de constitucionalidade: análise das emendas constitucionais no Brasil pós-1988. 12 de janeiro de 2018. 238 p. Doutorado. Faculdade de Direito, Universidade de São Paulo.

\section{RESUMO}

As principais críticas que a perspectiva do constitucionalismo político de Jeremy Waldron e Richard Bellamy lança em direção ao controle de constitucionalidade forte são fundamentadas na ideia de autogoverno, a qual não estaria presente quando as cortes constitucionais determinam uma interpretação vinculante aos demais poderes políticos. Ademais, tal vertente enfatiza a noção de igualdade política como elemento indispensável para as sociedades democráticas. Para o constitucionalismo político, a regra majoritária simples representa um importante mecanismo que impõe o igual respeito às visões políticas dos membros de um grupo. Apesar de aceitarem formas de controle de constitucionalidade que contam com a participação da manifestação parlamentar, os constitucionalistas políticos desconsideram a emenda constitucional como mecanismo para representar uma maneira de mitigar a supremacia judicial e possibilitar que haja uma participação mais significativa dos parlamentos na interpretação constitucional. No entanto, a partir do momento em que esses críticos recusam a análise em torno da potencialidade mitigatória da emenda, seus argumentos deixam de alcançar os sistemas jurídicos de controle forte com previsão de emenda constitucional. Em razão dessa lacuna teórica, a presente pesquisa partiu do seguinte problema: em que medida é possível analisar o controle de constitucionalidade de emenda constitucional a partir dos pressupostos democráticos do constitucionalismo político? Para tanto, demonstrou-se que o poder de reforma denota um poder singular, já que ele se diferencia tanto do poder constituinte originário como do poder constituído. No tocante às suas características, a possibilidade de exercício de emenda para a reversão da interpretação concedida previamente pelas cortes constitucionais significa um instrumento em face das críticas democráticas em torno do controle de constitucionalidade forte, já que as decisões judiciais poderiam ser reanalisadas mediante emenda. Entretanto, apesar desses pressupostos normativos democráticos em torno do poder de reforma, a mudança constitucional pode vir a ser reavaliada por uma instituição judicial em controle de constitucionalidade de emenda. Em razão disso, para que haja uma maior deferência em relação ao caráter democrático das emendas constitucionais, propôs-se uma forma de deliberação interna nas cortes que se dê a partir de maiorias qualificadas para o afastamento de emenda à constituição. Apesar da contrariedade dos constitucionalistas políticos às supermaiorias, concluiu-se que a possível desvantagem que eles veem na maioria qualificada para o parlamento não tem a mesma razão de ser para uma decisão judicial. A presunção da manutenção do status quo trazida pela regra de supermaioria, no controle de constitucionalidade de emenda, serve para tornar a decisão sobre o afastamento mais exigente, em razão da carga democrática que a emenda representa.

Palavras-chave: Constitucionalismo político. Emendas constitucionais inconstitucionais. Supermaioria. 
Democratization of judicial review: analysis of the constitutional amendments in Brazil after 1988. January 12, 2018. 238 p. Doctorate. University of São Paulo Law School.

\begin{abstract}
The key criticisms of strong judicial review made by Jeremy Waldron and Richard Bellamy, from the perspective of political constitutionalism, are based on the ideal of selfgovernment, which they say is absent when the constitutional courts define an interpretation which is binding to the other political powers. Moreover, their emphatic opinion is that political equality is an indispensable element in democratic societies. The political constitutionalist theory holds that the rule for a simple majority represents an important mechanism which imposes equal respect for the political views of the members of a group. Although they accept methods of judicial review in which parliamentary opinions are taken into account, political constitutionalists ignore the fact that a constitutional amendment is a mechanism which can mitigate the supremacy of the courts and enable parliaments to have a bigger say in interpreting the constitution. However, when these critics refuse to accept the potential of amendments to provide such mitigation, they exclude the legal systems of strong judicial review with constitutional amendments. Because of this gap in the theory, this paper is intended to address the following issue: to what extent is it possible to analyze the judicial review of a constitutional amendment on the basis of the democratic assumptions of political constitutionalism? To answer this question I have shown that the amending power denotes a singular power, which differs both from the original constituent power and from the constituted power. A feature of this singular power is that amendments can be used to reverse a previous interpretation handed down by the constitutional courts, and this provides an answer to democratic criticism of strong judicial review, since the courts' decisions can be reviewed upon an amendment. However, in spite of these democratic premises relating to the amending power, constitutional change can be reviewed by a judicial institution on the basis of judicial review of constitutional amendment. Accordingly, and in order for the democratic character of constitutional amendments to be treated with more deference, a form of internal deliberation by the courts has been proposed under which a super-majority can reject an constitutional amendment. Although political constitutionalists are opposed to super-majorities, the conclusion is that the possible disadvantage that they see in a qualified majority in parliament does not apply in the same way to a court decision. The presumption of maintenance of the status quo which a super-majority implies, when it comes to the judicial review of an amendment, serves to make a decision to reject the amendment more difficult, bearing in mind its democratic weight.
\end{abstract}

Keywords: Political constitutionalism; Unconstitutional constitutional amendments; Supermajority. 
Jairo Néia Lima. Democratizzazione del controllo della costituzionalità: analisi degli emendamenti costituzionali in Brasile dopo il 1988. 12 gennaio 2018. 240 p. Dottorato. Facoltà di Giurisprudenza, Università San Paolo.

\section{RIASSUNTO}

Le principali critiche che la prospettiva del costituzionalismo politico di Jeremy Waldron e Richard Bellamy rivolge verso il controllo della costituzionalità forte sono basate sull'idea di autogoverno, la quale non sarebbe presente quando le corti costituzionali determinano un'interpretazione vincolante agli altri poteri politici. Inoltre, questa linea enfatizza la nozione di uguaglianza politica come elemento alle società democratiche. Per il costituzionalismo politico, la regola maggioritaria semplice rappresenta un importante meccanismo che impone lo stesso rispetto alle visioni politiche dei membri di un gruppo. Sebbene accettino forme di controllo della costituzionalità che contano sulla partecipazione della manifestazione parlamentare, i costituzionalisti politici non considerano la riforma costituzionale un meccanismo che rappresenta un modo di mitigare la supremazia giudiziaria e rendere possibile una partecipazione più significativa dei parlamentari nell'interpretazione costituzionale. Tuttavia, dal momento in cui i critici rifiutano l'analisi intorno al potenziale di mitigazione dell'emendamento, non raggiungono i sistemi giuridici di forte controllo con previsione di riforma costituzionale. A causa di questa lacuna teorica, la presente ricerca è iniziata dal seguente problema: come è possibile analizzare il controllo della costituzionalità di uma reforma costituzionale a partire dalle presupposizioni democratiche del costituzionalismo politico? Per fare ciò, si è dimostrato che il potere della riforma denota un potere singolare, poiché differisce sia dal potere costituente originale sia dal potere costituito. Per quanto riguarda le sue caratteristiche, la possibilità di esercizio dell'emendamento per la riversione dell'interpretazione concessa precedentemente dalle corti costituzionali significa uno strumento di fronte alle critiche democratiche sul controllo di costituzionalità forte, poiché le decisioni giudiziarie potrebbero essere riesaminate per mezzo di uma riforma. Tuttavia, nonostante queste presupposizioni normative democratiche sul potere della riforma, il cambiamento costituzionale può essere rivalutato da un'istituzione giudiziaria che controlla la costituzionalità dell'emendamento. Per questo, affinché ci sia una maggiore attenzione al carattere democratico degli emendamenti costituzionali, è stata proposta una forma di deliberazione interna nei tribunali che succeda a partire da maggioranze qualificate per la rimozione dell'emendamento alla costituzione. Nonostante l'opposizione dei costituzionalisti politici alle super maggioranze, si è concluso che l'eventuale svantaggio che vedono nella maggioranza qualificata per il parlamento non ha la stessa ragione d'essere per una decisione giudiziaria. La presunzione di mantenere lo status quo introdotto dalla regola della super maggioranza, nel controllo della costituzionalità della riforma serve a rendere la decisione sul distanziamento più esigente, a causa del peso democratico che l'emendamento rappresenta.

Parole chiave: Costituzionalismo politico; Riforma costituzionali incostituzionali; super maggioranza. 



\section{SUMÁRIO}

INTRODUÇÃO

1 - CRÍTICAS AO CONTROLE JUDICIAL DE CONSTITUCIONALIDADE

1.1 - Premissa de Jeremy Waldron e Richard Bellamy 17

$\begin{array}{ll}1.2 \text { - As críticas de Jeremy Waldron } & 27\end{array}$

1.3 - As críticas ao constitucionalismo jurídico a partir de Richard Bellamy $\quad 37$

1.4 - Papel das cortes constitucionais para o constitucionalismo político $\quad 51$

1.5 - Conclusão do capítulo $\quad 63$

2 -ENTRE A FUNDAÇÃO E A EXECUÇÃO DA CONSTITUIÇÃO: O PODER DE REFORMA

68

2.1 - Teoria do poder constituinte $\quad 72$

2.2 - Natureza do poder de reforma constitucional 90

2.3 - Emendas constitucionais no Brasil 106

2.4 - Conclusão do capítulo 116

3 - EMENDAS CONSTITUCIONAIS INCONSTITUCIONAIS 124

$\begin{array}{ll}3.1 \text { - Limites substanciais ao poder de reforma } & 127\end{array}$

3.1.1 - Grau de interferência judicial no controle de emendas constitucionais $\quad 130$

3.1.2 - Entre maiorias do passado e juízes do presente 146

3.2 - Comportamento decisório do STF em emendas constitucionais 162

$\begin{array}{ll}3.3 \text { - Regra decisória de supermaioria } & 178\end{array}$

$\begin{array}{ll}3.4 \text { - Conclusão do capítulo } & 197\end{array}$

$\begin{array}{lr}\text { CONCLUSÃO } & 202\end{array}$

$\begin{array}{ll}\text { REFERENNCIAS } & 208\end{array}$

APÊNDICE A - Procedimentos metodológicos 229

APÊNDICE B - Emendas constitucionais por Título da CF/88 231

APÊNDICE C - Autores das PEC's convertidas em emenda 232

APÊNDICE D - Dados dos julgamentos das ADI's de emenda pelo STF 235 



\section{INTRODUÇÃO}

As normas constitucionais formam o documento político-jurídico fundador de uma nova sociedade política e estabelecem a estrutura, os princípios e os direitos fundamentais regentes da vida coletiva futura daquela comunidade. Diante da pretensão de durabilidade temporal, uma constituição não pode ser considerada absolutamente acabada a partir de sua promulgação. Pelo contrário, ela precisa estar sempre aberta dentro do seu tempo, conectada com os desígnios daqueles submetidos aos seus ditames. Essa aproximação, entretanto, corresponde a uma das tarefas mais árduas que as instituições políticas enfrentam quando realizam interpretação constitucional, pois lidam com pretensões sociais permeadas pela diversidade e pelos desacordos inerentes a qualquer sociedade comprometida com a democracia.

Contemporaneamente, o controle de constitucionalidade das leis exercido por órgãos judiciais não eleitos se estabeleceu como um importante mecanismo institucional para realizar a interpretação dessas normas constitucionais, principalmente dos direitos fundamentais. A presença de cortes e tribunais constitucionais na estrutura dos estados democráticos tornou mais complexo o jogo político que envolve a disputa pelo sentido da constituição. À lógica do processo político-parlamentar, acrescenta-se uma nova rodada decisória sobre o mesmo ato legislativo quando se executa o controle judicial de constitucionalidade. Nesse caso, a revisão judicial se desenvolve mediante raciocínio justificado com base em uma linguagem pertencente à tradição do direito constitucional e, também, por meio do compromisso com a jurisprudência. Em razão disso, os parlamentos não se apresentam como instituição exclusiva apta a vincular, mediante seus atos normativos, os atores públicos e a coletividade social, pois as decisões tomadas pelo controle judicial de constitucionalidade das leis também formam parte do parâmetro normativo que determina o respeito por parte dos atos infraconstitucionais.

No entanto, o produto da interpretação constitucional parlamentar e judicial advém de instituições configuradas de modo diverso, principalmente em relação à constituição de seus membros. Por um lado, os parlamentos são compostos por porta-vozes da coletividade, eleitos mediante um processo eleitoral. De outro, as cortes e tribunais constitucionais são compostas por experts, designados por instrumentos não eleitorais diretos. Essa diferença representa o ponto de partida dos debates teóricos em torno da 
legitimidade democrática do controle judicial de constitucionalidade das leis, pois o exercício dessa competência simboliza a contraposição entre as pretensões democráticas dos representantes e os limites a essa atuação reconhecidos por intermédio da revisão judicial.

O desenvolvimento da teoria constitucional do século XX, defensora da legitimidade do controle judicial de constitucionalidade, contou com a influência de autores como Ronald Dworkin e Jürgen Habermas. Juntamente com outros pensadores, eles apontaram diversos benefícios do exercício dessa competência pelas cortes e tribunais constitucionais, como: a proteção das pré-condições da democracia, dos direitos das minorias e da vontade originária do povo constituinte; o funcionamento como poder de veto na separação dos poderes; a indicação dos seus membros dentro de um sistema democrático; a exteriorização de uma democracia argumentativa e a inclinação dos juízes à proteção dos princípios constitucionais, dentre outros. Essas vantagens possibilitaram o progresso da proteção dos direitos fundamentais bem como do regime democrático em diversas partes do mundo, pois o processo parlamentar não se encontra imune à captura de grupos políticos guiados exclusivamente pelo autointeresse.

Não obstante os estudos direcionados à exploração das potencialidades democráticas das cortes e tribunais constitucionais, a presente pesquisa se desenvolve no sentido oposto, ou seja, a partir da análise dos argumentos dos autores críticos à legitimidade do controle judicial de constitucionalidade em sociedades democráticas. Nesse ponto, serão analisados os argumentos de Jeremy Waldron e Richard Bellamy, os quais podem ser classificados como pertencentes à corrente de pensamento do constitucionalismo político, principalmente em razão do realce concedido ao processo político-parlamentar na definição da abrangência dos direitos fundamentais. Optou-se por realizar um recorte de pesquisa restrito a Waldron e Bellamy, pois são autores contemporâneos, de tradições de pensamento distintas (liberal e republicana, respectivamente) e que têm pautado o debate teórico sobre a questão da legitimidade do controle de constitucionalidade.

Frise-se, entretanto, que o tratamento dessa perspectiva não significa adesão à discussão em torno do problema da legitimidade da revisão judicial (legítimo v. não legítimo), dado que a teoria constitucional empregou significativa energia argumentativa nesse empreendimento. Diversamente de uma investigação sobre a legitimidade, esta pesquisa se direciona para uma leitura do controle de constitucionalidade a partir das críticas dos autores mencionados, a fim de demonstrar formas de potencializá-lo 
democraticamente. Por essa razão, toma-se como ponto de partida a presença das cortes e tribunais constitucionais nos diversos sistemas constitucionais democráticos pelo mundo e se questiona em que medida o controle judicial de constitucionalidade pode ser exercido a partir da inclusão das críticas feitas pelo constitucionalismo político de Jeremy Waldron e Richard Bellamy?

Para responder o problema da pesquisa, delimitou-se o objeto para testar a hipótese de que os argumentos críticos de Waldron e Bellamy, apesar de não rejeitarem a revisão judicial por completo e se inclinarem para formas de controle que incluam a manifestação parlamentar, deixam de enfrentar o potencial mitigatório que a emenda constitucional teria em face da atuação da interpretação constitucional das cortes e tribunais constitucionais. Essa lacuna acoberta um problema de desafios específicos decorrentes das limitações procedimentais e materiais ao poder de reforma e do exercício de controle de constitucionalidade de emenda constitucional. Se a revisão judicial de legislação infraconstitucional já representa uma tensão entre democracia e constitucionalismo, com maior razão se deduz que o controle de constitucionalidade de emenda constitucional constitui um nível intensificado desse embate. No entanto, conforme se demonstrará nesta pesquisa, essa discussão não está presente no referencial teórico de Waldron e Bellamy. Ao não abordarem a situação das emendas, o constitucionalismo político deixa de fora a explicação sobre o modo de atuação de cortes e tribunais constitucionais em torno da revisão judicial de emenda constitucional. Diante disso, a presente pesquisa aborda as especificidades relativas ao controle de constitucionalidade de emenda constitucional e, estritamente, analisa as regras de votação majoritária simples e qualificada que as cortes e tribunais constitucionais utilizam para a declaração de inconstitucionalidade de emenda.

O modelo argumentativo empregado para alcançar esse empreendimento teórico se baseia na leitura do controle de constitucionalidade a partir das debilidades democráticas apontadas pelo constitucionalismo político. Além disso, tem por objetivo a explicação dos fatores que contribuem para o exercício do controle de constitucionalidade de emenda constitucional deferente às qualidades do processo político-parlamentar. No tocante aos procedimentos metodológicos, a pesquisa é essencialmente bibliográfica, todavia, faz uso de pesquisa empírica quantitativa e qualitativa para tratar das especificidades brasileiras em relação ao emendamento à Constituição (1988 a 2016) e ao comportamento do Supremo Tribunal Federal no controle de constitucionalidade de emenda constitucional. 
A partir dessa metodologia, tem-se o seguinte plano de trabalho: o primeiro capítulo descreve os argumentos e as premissas teóricas de Waldron e Bellamy. Com esse detalhamento, identificam-se os pontos de concessão que eles fazem à revisão judicial e se revela a importante lacuna sobre o papel da emenda constitucional nos desenhos institucionais democráticos.

O recorte metodológico sobre a emenda constitucional tem suas razões explicitadas a partir do segundo capítulo, quando, tanto o poder constituinte originário, como o poder de reforma, são analisados sob perspectivas democráticas relacionadas aos diferentes níveis de engajamento deliberativo na produção normativa. Paralelamente à discussão de caráter normativo, apresenta-se investigação empírica em torno das características das emendas constitucionais no Brasil desde a Constituição de 1988.

Por fim, o terceiro capítulo enfrenta as dificuldades na assunção do controle de constitucionalidade de emenda constitucional, principalmente em face de limites materiais explícitos e implícitos. Nesse ponto, a jurisprudência comparada serve de auxílio para esclarecimento da intensidade da interferência judicial na emenda. Quanto ao Brasil, são expostos dados empíricos sobre: os argumentos utilizados pelo Supremo Tribunal Federal para assumir o controle de emenda; as ações diretas de inconstitucionalidade com objeto a emenda constitucional e as respectivas cláusulas pétreas protegidas.

Encerra-se a pesquisa com a indicação de uma proposta normativa para o controle de emenda por meio da investigação em torno da utilização do quórum supermajoritário na deliberação interna das cortes e tribunais constitucionais. Esse mecanismo corresponde a um instrumento essencialmente formal, isso significa dizer que a via democrática eleita para o controle de emenda não invoca a assunção de determinado método de interpretação constitucional, porque se assume que as escolhas interpretativas estão sujeitas a uma certa discricionariedade judicial, não autorizada pela regra formal de quórum de votação.

Não obstante o diálogo com a realidade nacional, os argumentos desenvolvidos na tese pretendem explicar os ordenamentos constitucionais autorizadores do controle judicial de constitucionalidade de emenda constitucional, os quais declaram a inconstitucionalidade por método agregativo de votos. Por essa razão, as discussões nacionais são tratadas em itens específicos do trabalho.

Por fim, a democratização do controle de constitucionalidade compreendida neste trabalho encontra-se relacionada com a valorização do processo político dos parlamentos e com a ideia de desacordo institucional, na qual cortes e parlamentos dependem de mecanismos para exteriorizarem o dissenso entre suas decisões em torno da interpretação 
constitucional. Esses dois elementos não compõem toda a potencialidade reconhecida pelas diversas teorias democráticas dos instrumentos de participação política não institucionalizados formalmente. A despeito desse caráter restrito, o conceito de democratização adotado serve para permear as diversas instituições políticas de sentido comprometido com a democracia. 


\section{CONCLUSÃO}

O principal mérito que a perspectiva do constitucionalismo político proporcionou à teoria constitucional contemporânea corresponde à desmistificação do controle judicial de constitucionalidade forte como instrumento indispensável para o avanço de direitos fundamentais em sociedades democráticas. Isso porque, autores como Jeremy Waldron e Richard Bellamy, ressaltam que as cortes constitucionais compartilham da mesma falibilidade presente nas instituições parlamentares. Os direitos que estão em jogo em uma disputa sobre a interpretação constitucional são objeto de desacordo constitutivo das democracias, por essa razão, importa, com maior ênfase, a abertura ao dissenso institucional, ao invés da confiança no acerto de uma única instituição. Ao assumir essa premissa, a presente pesquisa buscou evadir-se do debate em torno da instituição legítima para realizar a interpretação constitucional e se direcionou para as democracias existentes com cortes constitucionais assentadas na estrutura política.

No entanto, o resgate que o constitucionalismo político ensejou em favor dos parlamentos se insere em um lapso temporal de crescente desconfiança nessas instituições. Dentre outros fatores, a crise de representação parlamentar presente em várias partes do mundo decorre das consequências da globalização para as instituições políticas nacionais, pois as decisões mais importantes que repercutem na vida das pessoas encontram-se, cada vez mais, sediadas fora das instituições tradicionais, como os parlamentos. A globalização econômica favoreceu o policentrismo decisório concorrente com o Estado nacional, como é o caso da atuação de cortes internacionais e organizações multilaterais. Em razão disso, os espaços públicos nacionais de deliberação conjunta se enfraquecem, pois as decisões políticas são pulverizadas entre diversos atores comunitários, privados e supranacionais.

Além disso, as críticas às deficiências democráticas identificadas pelo constitucionalismo político na atuação das cortes constitucionais são limitadas a uma leitura de accountability com ênfase no processo eleitoral e parlamentar, ou seja, a revisão judicial não se enquadraria em sociedades democráticas comprometidas com o desacordo, pois as cortes constitucionais tomam decisões políticas (interpretação constitucional dos direitos fundamentais) por meio de indivíduos não detentores da legitimidade eleitoral e não sujeitos à diversidade de opiniões presente nos parlamentos. Nesse último aspecto, Jeremy Waldron ressalta a institucionalização da oposição como instrumento da exteriorização do dissenso na formação da política ordinária e Richard Bellamy destaca o 
papel dos partidos políticos na promoção do debate de interesses diversos, tanto nas eleições como no processo legislativo. A perspectiva de Waldron e Bellamy, no entanto, deixa de enfrentar os desafios impostos pela teoria da representação democrática contemporânea em relação ao processo eleitoral e à participação popular que ocorre fora das instituições formais de poder. Ademais, principalmente em Waldron, o exercício de accountability horizontal externo entre poderes, não está presente como argumento potencialmente vantajoso às cortes constitucionais. Verifica-se, contudo, que Richard Bellamy se encontra mais próximo dessa associação, pois seu arranjo político republicano, ao garantir a "oitiva da outra parte", demanda a potencialização dos mecanismos de controle recíproco (horizontais) de poder.

A presente pesquisa se desenvolveu a partir da lacuna teórica relativa ao papel da emenda constitucional na perspectiva de Waldron e Bellamy. Ao se seguir a linha de raciocínio desses autores de aceite do desempenho da revisão judicial, desde que aberta a respostas legislativas, esperava-se deles alguma análise em torno da emenda constitucional como instrumento para os parlamentos reverterem o entendimento das cortes constitucionais e, com isso, relativizar a supremacia judicial do controle de constitucionalidade. Entretanto, em razão das exigências supermajoritárias para a aprovação de emenda constitucional, Waldron e Bellamy não reconhecem o caráter democrático no processo de mudança constitucional. Segundo esses autores, a regra de supermaioria não concede tratamento equânime das opiniões em disputa, pois favorece a manutenção do status quo, ao exigir maiores esforços políticos (maioria qualificada) dos apoiadores da alteração constitucional. No entanto, quando deixam de explorar a emenda constitucional, Waldron e Bellamy limitam a abrangência dos seus argumentos, uma vez que a emenda constitucional representa um importante instrumento político disseminado nos diversos ordenamentos constitucionais do mundo.

A partir desse ponto de partida, a presente investigação demonstrou que as críticas elaboradas pelo constitucionalismo político de Jeremy Waldron e Richard Bellamy impõem um controle de constitucionalidade que compartilhe a interpretação constitucional com o parlamento. No tocante ao controle de emenda constitucional, essa deferência pode ser dada mediante a regra de supermaioria na decisão que reconhece a inconstitucionalidade de emenda.

Portanto, dentre as contribuições essenciais apresentadas por essa pesquisa à teoria constitucional contemporânea que se dedica à análise do tema, encontram-se: 
$1^{\text {a) }}$ Reforço da natureza distinta do poder de reforma: o poder de reforma constitucional representa o poder constituinte derivado e se distingue, tanto do poder constituinte originário, como dos poderes constituídos. Não significa poder constituinte originário, pois não tem a características da incondicionalidade jurídica e também não busca fundar uma nova ordem constitucional. Não se enquadra, ainda, como poder constituído, pois objetiva a alteração das normas constitucionais, hierarquicamente superiores à normas ordinárias dos poderes constituídos. O poder de reforma encontra-se limitado apenas pelas restrições procedimentais e, quando presentes, pelos conteúdos eleitos pelo constituinte originário como não alteráveis mediante emenda. Desse modo, o poder de reforma reside em uma zona intermediária entre o constituinte originário e os poderes constituídos. Por essa razão, demanda um engajamento deliberativo diverso, superior aos poderes constituídos, em um momento constitucional exclusivo para a emenda.

$2^{\text {a }) ~ T e n s a ̃ o ~ e s p e c i ́ f i c a ~ d o ~ c o n t r o l e ~ d e ~ c o n s t i t u c i o n a l i d a d e ~ d e ~ e m e n d a ~}$ constitucional: o estabelecimento de limites ao poder de reforma enseja o enfrentamento da questão em torno da forma pela qual tais restrições serão sancionadas pelas instituições políticas. Conforme demonstrado na pesquisa, alguns países abrem mão do exercício dessa competência pelas cortes constitucionais (EUA e França), já outros, independentemente de previsão constitucional expressa, acolheram o controle de constitucionalidade de emenda constitucional por intermédio de interpretação dada pelas próprias cortes (Alemanha, Índia, Colômbia e Brasil). Subjacente a essa atuação judicial, existe uma tensão particular entre constitucionalismo e democracia não captada pelo constitucionalismo político. Quando as cortes constitucionais realizam o controle de emenda sob a justificativa de proteção à identidade ou estrutura constitucional, elas definem o limite que caracterizar um novo poder constituinte originário. Essa colisão se torna ainda mais exacerbada a partir do momento em que as cortes passam a proteger os limites implícitos ao poder de reforma.

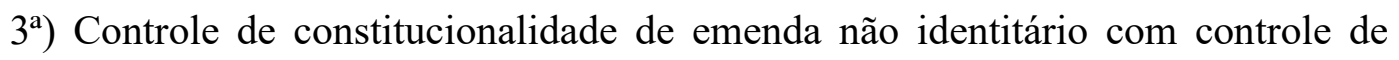
constitucionalidade de norma infraconstitucional: em face da especificidade democrática do poder de reforma e das tensões que o seu controle revela, o exercício dessa competência não pode ser equiparado ao controle de constitucionalidade de legislação infraconstitucional, pois são objeto com naturezas distintas, em que a carga democrática está presente com maior vigor na emenda constitucional. Por essa razão, o controle de constitucionalidade de emenda não identitário simboliza a decorrência necessária da assunção das duas contribuições anteriores. Dentre as diversas formas de se delimitar um 
arranjo próprio para o controle de emenda, a presente pesquisa optou pela defesa da supermaioria para o reconhecimento da inconstitucionalidade de emenda constitucional. A regra de supermaioria, conforme mencionado, se consubstancia em um mecanismo de decisão que favorece uma das opções em debate, qual seja, a manutenção do status quo. Se, por um lado, essa característica não trata de forma equânime os representantes no momento da votação de uma emenda constitucional, de outro, não há qualquer violação à igualdade de opiniões nas cortes, pois elas não atuam em uma base representacional. A presunção de manutenção do status quo no controle de emenda configura respeito e deferência aos pressupostos normativos democráticos desse ato fruto do poder constituinte derivado. Subjacente a esse argumento, portanto, demonstrou-se que um elemento não democrático para o constitucionalismo político (regra de supermaioria) pode ser desenvolvido em favor do próprio constitucionalismo político, quando aplicado no âmbito do controle de constitucionalidade de emenda.

Cada uma dessas contribuições teóricas, no entanto, quando direcionadas para a dinâmica institucional brasileira, precisam levar em conta as seguintes peculiaridades nacionais, respectivamente:

$1^{\text {a) }}$ O emendamento nacional pós 1988 se caracterizou pela constância de sua ocorrência (alta taxa de emendas) e, em seu conteúdo, pela constitucionalização de um elevado número de políticas de governo. Esse fato gerou a trivialização do momento específico do poder de reforma, obscurecendo, assim, sua natureza diversa em relação aos poderes constituídos. Ademais, a potencialidade democrática da emenda constitucional no Brasil sofre pela ausência de previsão constitucional de participação popular, tanto na propositura, como na aprovação do ato.

$2^{\mathrm{a}}$ ) O Supremo Tribunal Federal, ao assumir a competência para o controle de constitucionalidade de emenda constitucional em razão da proteção às cláusulas pétreas, abriu caminhos para que os limites constitucionais explícitos ao poder de reforma fossem judicialmente tutelados. A pesquisa empírica sobre o comportamento decisório do Supremo Tribunal Federal apurou a prevalência das decisões concessivas de medida cautelar em comparação às denegatórias, as quais se encontram inseridas em um contexto mais amplo de declínio no tempo. Esses números indicam que as emendas constitucionais, quando questionadas em ADI, tendem a ser substituídas por um provimento judicial mais célere, o qual é mantido no julgamento final dessas ações, quando elas não perdem seu objeto. A maioria das cautelares prejudicadas são fundamentadas no art. 12 , da Lei $\mathrm{n}^{\mathrm{o}}$ 9.868/99, o qual representa um instrumento excepcional de celeridade. No entanto, o STF, 
ao estabelecer uma prática rotineira, tem desvirtuado esse instrumento processual de remessa do caso ao Plenário. Com isso, a Corte fomenta a indecidibilidade dos casos por conta da sobrecarga de processos presentes no órgão.

Além disso, ao interpretar a cláusula pétrea "direitos e garantias individuais", o Supremo Tribunal Federal reconheceu, com a autorização do art. $5^{\circ}, \S 2^{\circ}$ da Constituição Federal, a presença de direitos fundamentais explícitos e implícitos por todo o texto constitucional. Por essa razão, aderiu a uma concepção ampla de cláusulas pétreas, restrita, apenas, à proteção do seu núcleo essencial. Essa medida de contenção, entretanto, mostrase presente somente após um percurso interpretativo prévio de assunção da competência do controle de constitucionalidade de limites formais/materiais e explícitos/implícitos à emenda constitucional. Ainda que esses obstáculos precedentes fossem afastados, não se pode deixar de considerar que a ideia de proteção limitada ao núcleo essencial das cláusulas pétreas provém de interpretação judicial, a qual depende da composição dos membros do STF que sustentem essa visão no tempo. Essa crítica também é cabível em relação às técnicas interpretativas de decisão utilizadas pelo STF para relativizar a força vinculante dos seus pronunciamentos em controle de constitucionalidade geral.

Nota-se, assim, que a interferência do Supremo Tribunal Federal no âmbito das emendas constitucionais decorre de um movimento expansivo próprio, resultante de interpretação judicial, mas, também, decorrente de instrumentos constitucionalmente previstos, como o art. $5^{\circ}, \S 2^{\circ}$. Assim, na esteira da jurisprudência da Corte, a tensão entre constitucionalismo e democracia que a Constituição Federal de 1988 incorpora, ao menos na questão específica dessa pesquisa, se resolve por meio da domesticação dos impulsos democráticos em prol do que o STF determina como norma constitucional.

$3^{\text {a) }}$ A diferenciação entre o controle de constitucionalidade de emenda e de norma infraconstitucional não está presente de maneira significativa na atuação do Supremo Tribunal Federal. Ao se somar o caráter aberto e implícito das cláusulas pétreas "direitos e garantias individuais" com as demais disposições do art. $60, \S 4^{\circ}$, as normas de referência para a compatibilidade entre emenda e Constituição se tornam consideravelmente extensas. Ocorre que a amplitude do parâmetro constitucional se caracteriza como um elemento do controle de constitucionalidade das leis, as quais estão subordinadas a todas as normas formalmente constitucionais. A partir do momento em que as cláusulas pétreas são entendidas pelo STF como potencialmente abrangentes, os controles de emenda e de lei tornam-se praticamente indistinguíveis, apesar da diferença normativa do objeto de revisão judicial. Conforme mencionado, técnicas interpretativas possuem eficácia limitada para 
moderar a atuação do controle de constitucionalidade, pois dependem, essencialmente, de uma atitude deferente por parte dos membros que compõem o STF. Nesse sentido, tais técnicas podem não contribuir para propiciar um controle de constitucionalidade não identitário. No âmbito da Corte, a tese de supermaioria para afastamento da emenda constitucional do ordenamento jurídico traz consigo um desafio adicional em razão dos diversos estudos empíricos recentes descortinando a atuação isolada e cada vez mais individual dos Ministros, tornando o colegiado um órgão progressivamente deserto e menos deliberativo.

Em suma, as peculiaridades nacionais demonstram que as emendas constitucionais e seu controle de constitucionalidade no Brasil estão distantes dos pressupostos normativos indicados nessa pesquisa. Não obstante, eles servem para guiar as futuras alterações nesses institutos a fim de potencializar os elementos democráticos no interior do sistema constitucional nacional. 


\section{REFERÊNCIAS}

ABRANCHES, Sérgio. Presidencialismo de coalizão: o dilema institucional brasileiro. Dados, v. 31, nº 1, 1988.

ACKERMAN, Bruce. Nós, o povo soberano: fundamentos do direito constitucional. Belo Horizonte: Del Rey, 2006.

ÁFRICA DO SUL. Constitution of the Republic of South Africa, 1996. Disponível em: https://www.gov.za/documents/constitution-republic-south-africa-1996-chapter-4parliament. Acesso em: 9/9/17.

AGNÉ, Hans. Democratic founding: We the people and the others. International Journal of Constitutional Law, v. 10, $\mathrm{n}^{\mathrm{o}}$ 3, 2012.

AGRA, Walber de Moura. Fraudes à Constituição: um atentado do poder reformador. Porto Alegre: Sérgio Fabris, 2000.

ALBERT, Richard. Nonconstitutional amendments. Canadian Journal of Law and Jurisprudence, v. 22, nº 1, 2009. 59:2, 2013.

. The expressive function of constitutional amendment rules. McGill Law Journal, $\overline{2014 \mathrm{a}}$.

. The structure of constitutional amendment rules. Wake Forest Law Review, v. 49,

. Constitutional disuse or desuetude: the case of article V. Boston University Law Review, v. 94, 2014.

The progressive era of constitutional amendment. In: BLANCHET, Luiz Alberto; HACHEM, Daniel Wunder; SANTANO, Ana Claudia. Eficiência e ética na administração pública. Curitiba: Íthala, 2015a.

. Amending constitutional amendment rules. International Journal of Constitutional Law, v. 13, no 3,2015 b.

. How a court becomes supreme: defending the constitution from unconstitutional amendments. Disponível em: https://papers.ssrn.com/sol3/papers.cfm?abstract id=2975832. Acesso em: 13/7/17.

Constitutional amendment and dismemberment. Disponível em: https:/papers.ssrn.com/sol3/papers.cfm?abstract_id=2875931. Acesso em: 5/11/17.

ALCALÁ, Humberto Nogueira. Le sentencia del Tribunal Constitucional en Chile: análisis y reflexiones jurídicas. Estudios Constitucionales, a. 8, nº 1, 2010.

ALEMANHA. Basic Law for the Federal Republic of Germany. Disponível em: https://www.btg-bestellservice.de/pdf/80201000.pdf. Acesso em: 14/10/17. 
. Act on the Federal Constitutional Court, 12/3/51. Disponível em: http://www.bundesverfassungsgericht.de/SharedDocs/Downloads/EN/Gesetze/BVerfGG.p df? blob=publicationFile\&v=5. Acesso em: 14/10/17.

ALVES, Fernando de Brito. Constituição e Participação Popular: a construção históricodiscursiva do conteúdo jurídico-político da democracia como direito fundamental. Curitiba: Juruá, 2013.

; LIMA, Jairo Néia. Quando o poder constituinte desafia os poderes constituídos: uma abordagem filosófica sobre a confiança democrática na desobediência civil e no direito ao protesto social. Revista Brasileira de Direito, v. 13, $\mathrm{n}^{\circ}$ 1, 2017.

AMAR, Akhil Reed. The consent of the governed: constitutional amendment outside article V. Columbia Law Review, v. 94, 1994.

America's unwritten Constitution: the precedents and principles we live by. New York: Basic Books, 2012.

AMARAL JÚNIOR, José Levi Mello. Controle de Constitucionalidade Evolução Brasileira determinada pela falta do Stare Decisis. Revista dos Tribunais, v. 920. São Paulo, 2012.

AMHLAIGH, Cormac Mac. Putting political constitutionalism in its place. International Journal of Constitutional Law, v. 14, nº 1, 2016.

ANGOLA. Constituição da República da Angola, 2010. Disponível em: www.mirex.gov.ao/download.aspx?id=533\&tipo=legislacao. Acesso em: 18/8/17.

ARATO, Andrew. Post Sovereign Constitutional Making: learning and legitimacy. Oxford University Press, 2016.

ARAÚJO, Cícero. O processo constituinte brasileiro, a transição e o poder constituinte. Lua Nova, ${ }^{\circ} 88,2013$.

ARGUELLES, Diego Werneck; RIBEIRO, Leandro Molhano. O Supremo Individual: mecanismos de atuação direta dos Ministros sobre o processo político. Direito, Estado e Sociedade, $\mathrm{n}^{\mathrm{o}} 46,2015$.

ARISTÓTELES. A Política. Bauru: Edipro, 2009.

ÁUSTRIA. Constituição. Disponível em: https://www.constituteproject.org/constitution/Austria_2013.pdf?lang=en. Acesso em: 15/10/17.

BACHOFF, Otto. Normas Constitutionais Inconstitucionais. Coimbra: Almedina, 2007.

BAILEY, Saki; MATTEI, Ugo. Social Movements as Constituent Power: The Italian Struggle for the Commons. Indiana Journal of Global Legal Studies, v. 20, nº 2, 2013. 
BARACHO, José Alfredo de Oliveira. Teoria geral da revisão constitucional e Teoria da constituição originária. Revista de Direito Administrativo, v. 198, 1994.

BARAK, Aharon. Unconstitutional Constitutional amendments. Israel Law Review, v. 44, 2011.

BARANGER, Denis. The language of eternity: constitutional review of the amending power in France (or the absence thereof). Jus Politicum - Revue de droit politique, $\mathrm{n}^{\mathrm{o}} 5$, 2010.

BARBOSA, Leonardo Augusto de Andrade Barbosa. História constitucional brasileira: mudança constitucional, autoritarismo e democracia no Brasil pós-1964. Brasília: Edições Câmara, 2012.

BARBOZA, Estefầnia Maria de Queiroz. Precedentes judiciais e segurança jurídica: fundamentos e possibilidade para a jurisdição constitucional brasileira. São Paulo: Saraiva, 2014.

BAREIN. Bahrain Constitution, 2002. Disponível em: https://www.constituteproject.org/constitution/Bahrain 2002.pdf. Acesso: 20/8/17.

BARROSO, Luís Roberto. A razão sem voto: o Supremo Tribunal Federal e o governo da maioria. In: SARMENTO, Daniel (Coord.). Jurisdição constitucional e política. Rio de Janeiro: Forense, 2015.

BEÇAK, Rubens. Democracia: Hegemonia e Aperfeiçoamento. São Paulo: Saraiva, 2014.

A separação de poderes, o Tribunal Constitucional e a "judicialização da política". Revista da Faculdade de Direito da Universidade de São Paulo, v. 103, 2008.

BECHARA, Evanildo. Moderna Gramática Portuguesa. Rio de Janeiro: Nova Fronteira, 2015.

BELLAMY, Richard. Political Constitutionalism: a republican defence of the constitutionality of democracy. United Kingdom: Cambridge University Press, 2007.

. Republicanism, Democracy, and Constitutionalism. In: LABORDE, Cécile; MAYNOR, John (Eds.). Republicanism and Political Theory. Blackwell, 2008.

. Political constitutionalism and the Human Rights Act. International Journal of Constitutional Law, v. 09, n. 01, 2011.

. The democratic legitimacy of international humans rights conventions: political constitutionalism and the Hirst case. In: FOLLESDAL, Andreas; SCHAFFER, Johan Karlsson; ULFSTEIN, Geir (Eds.). The Legitimacy of International Human Rights Regimes: Legal, Political and Philosophical Perspectives, Cambridge University Press, $2013 \mathrm{a}$. 
- The democratic qualities of courts: a critical analysis of three arguments. Representation, v. 49, $\mathrm{n}^{\mathrm{o}}$ 3, $2013 \mathrm{~b}$.

. The democratic legitimacy of International Human Rights Conventions: Political Constitutionalism and the European Convention on Human Rights. The European Journal of International Law, v. 25, $\mathrm{n}^{\circ}$ 4, 2014.

. Turtles all the way down? Is the political constitutionalist appeal to disagreement self-defeating? A reply to Cormac Mac Amhlaigh. International Journal of Constitutional Law, v. 14, no 1, 2016.

BELTRÁN, Enrique Navarro. El control de constitucionalidade de las leyes en Chile (1811-2011). Cuadernos del Tribunal Constitucional, $\mathrm{n}^{\circ}$ 43, a. 2011.

BERCOVICI, Gilberto. Soberania e Constituição: para uma crítica do constitucionalismo. $2^{a}$ ed. São Paulo: Quartier Latin, 2013.

BERNAL, Carlos. Unconstitutional constitutional amendments in the case study of Colombia: an analysis of the justification and meaning of the constitutional replacement doctrine. International Journal of Constitutional Law, v. 11, nº 2, 2013.

BERTOMEU, Juan F. Gonzalez. Against the core of the case: structuring the evaluation of judicial review. Legal Theory, no 17, 2011.

BISARYA, Sumit. Performance of constitutions transitional provisions. In: GINSBURG, Tom; HUQ, Aziz (Ed.). Assessing Constitutional Performance. Cambridge University Press, 2016.

BÖCKENFÖRDE, Ernst-Wolfgang. Constitutional and Political Theory: selected writings. Oxford Scholarship Online, 2017.

BRADBURY, John Charles; JOHNSON, Joseph. Do supermajority rules limit or enhance majority tyranny? Evidence from the US States, 1960-1997. Public Choice, 127, 2006.

BRANDÃO, Rodrigo. Direitos fundamentais, democracia e cláusulas pétreas. Rio de Janeiro: Renovar, 2008.

. Supremacia judicial versus diálogos constitucionais: a quem cabe a última palavra sobre o sentido da constituição? Rio de Janeiro: Lumen Juris, 2012.

BRASIL. Assembleia Nacional Constituinte. Emendas Populares, v. 258, 1988.

BRASIL. Câmara dos Deputados. Proposta de Emenda à Constituição - PEC no 33/11. Apresentação em 25/5/11. Disponível em: http://www.camara.gov.br/proposicoesWeb/fichadetramitacao?idProposicao=503667.

Acesso em: 10/11/17.

Supremo Tribunal Federal. Habeas corpus $n^{\circ}$ 18.178. Rel: Min: Hermenegildo de Barros. DJ: 1\%/10/26. 
$\overline{\mathrm{DJ}:} 8 / 10 / 80$.

. Mandado de segurança $n^{\circ}$ 20.257. Rel. para acórdão: Min. Moreira Alves. $\overline{3 / 4 / 91}$.

$\overline{\mathrm{DJ}}: 15 / 9 / 05$.

. Ação direta de inconstitucionalidade $n^{\circ}$ 466. Rel: Min. Celso de Mello. DJ:

. Ação direta de inconstitucionalidade $n^{\circ}$ 2797. Rel: Min. Menezes Direito.

. Recurso Extraordinário n 466.343. Rel: Min. Cezar Peluso. DJ: 3/12/08.

- Agravo Regimental no Recurso Extraordinário com Agravo no 639337.

Rel: Min. Celso de Mello. DJ: 15/9/11.

Agravo Regimental no Recurso Extraordinário $n^{\circ}$ 634643. Rel: Min. Joaquim Barbosa. DJ: 13/8/12.

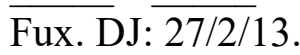

Agravo Regimental no Recurso Extraordinário no 642536. Rel: Min. Luiz

$\overline{1 \% / 10 / 15}$

. Ação direta de inconstitucionalidade no 5105. Rel: Min. Luiz Fux. DJ:

. Ação direta de inconstitucionalidade. Rel: Min. Luiz Fux. DJ: 24/2/16.

BREGA FILHO, Vladimir. Direitos Fundamentais na Constituição de 1988: Conteúdo Jurídico das Expressões. São Paulo: Juarez de Oliveira, 2002.

BUCHANAN, James; TULLOCK, Gordon. The Calculus of Consent: logical foundations of constitutional democracy. Indianapolis: Liberty Fund, 1962.

BULGÁRIA. Bulgaria's Constitution of 1991. Disponível em: https://www.constituteproject.org/constitution/Bulgaria_2015.pdf?lang=en. Acesso em: 9/9/17.

BULOS, Uadi Lammêgo. Dez anos de Constituição: em torno das cláusulas de inamovibilidade. Revista de Direito Administrativo, v. 217, 1999.

. Constituição Federal anotada. 9a ed. São Paulo: Saraiva, 2009.

CABO VERDE. Constituição da República de Cabo Verde, 1992. Disponível em: portais.parlamento.cv/rppd/legislacao/cr.pdf. Acesso em: 20/8/17.

CAGgIANO, Monica Herman Salem. Direito Parlamentar e Direito Eleitoral. Barueri: Manole, 2004.

CAMINKER, Evan. Thayerian deference to Congress and Supreme Court supermajority rules: lessons from the past. Indiana Law Journal, v. 78, 2003. 
CAPPELLETTI, Mauro. O controle judicial de constitucionalidade das leis no direito comparado. Porto Alegre: Sérgio Fabris, 1984.

CARRÉ DE MALBERG, Raymond. Teoria general del estado. $2^{\mathrm{a}}$ ed. México: Fondo de Cultura Económica, 1998.

CASSEB, Paulo Adib. Controle preventivo de constitucionalidade no Brasil. Revista Nomos, v. 29, n 2, 2009.

CERVI, Emerson Urizzi. Atualização dos limites dos distritos: uma crítica ao sistema de representação majoritária dos Estados Unidos. Revista de Sociologia Política, nº 21, 2003.

CHILE. Constitución Política de la República de Chile, 1980. Disponível em: https://www.leychile.cl/Navegar?idNorma=242302\#920. Acesso em: 9/9/17.

CHRISTIANO, Thomas. Waldron on Law and Disagreement. Law and Philosophy, v. 19, $\mathrm{n}^{\mathrm{o}} 4,2000$.

CHUEIRI, Vera Karam de. Nas trilhas de Carl Schmitt (ou nas Teias de Kafka): Soberania, Poder Constituinte e Democracia Radical. In: FONSECA, Ricardo Marcelo (Org.). Repensando a Teoria do Estado. Belo Horizonte: Fórum, 2004.

; GODOY, Miguel. Constitucionalismo e Democracia: soberania e poder constituinte. Revista de Direito GV, nº 6, 2010.

. Constituição radical: uma ideia e uma prática. Revista da Faculdade de Direito $\overline{U F P R}, \mathrm{n}^{\circ} 58,2013$.

COELHO, Luiz Fernando. Direito Constitucional e Filosofia da Constituição. $1^{\text {a }}$ ed. Curitiba: Juruá, 2014.

COLLETT, Teresa Stanton. Judicial Independence and accountability in an age of unconstitutional constitutional amendments. Loyola University Chicago Law Journal, v. 41, 2010.

COLÔMBIA. Constitución Política de Colombia, 1991. Disponível em: http://www.corteconstitucional.gov.co/?bTy. Acesso em: 25/6/17.

. Corte Constitucional. Sentencia C-551/03, DJ: 9/7/03. Disponível em: http://www.corteconstitucional.gov.co/relatoria/2003/C-551-03.htm. Acesso em: 25/6/17.

Sentencia C-970/04, DJ: 7/10/04. Disponível em: $\underline{\mathrm{http}: / / w w w . c o r t e c o n s t i t u c i o n a l . g o v . c o / r e l a t o r i a / 2004 / c-970-04 . h t m}$. Acesso em: 25/6/17.

Sentencia C-141/10, DJ: 26/2/10. Disponível em: http://www.corteconstitucional.gov.co/relatoria/2010/c-141-10.htm. Acesso em 25/6/17.

COLÓN-RÍOS, Joel. Weak constitutionalism: democratic legitimacy and the question of constituent power. Routledge, 2012. 
COSTA, Alexandre Araújo. O poder constituinte e o paradoxo da soberania limitada. Teoria e Sociedade, $\mathrm{n}^{\circ}$ 19.1, 2011.

; BENVINDO, Juliano Zaiden. A quem interessa o controle concentrado de constitucionalidade? O descompasso entre teoria e prática na defesa dos direitos fundamentais. Social Science Research Network, 2014.

COSTA, Pietro. Poucos, muitos, todos: lições de história da democracia. Curitiba: UFPR, 2012.

COSTA E SILVA, Gustavo Just. Os limites da reforma constitucional. Rio de Janeiro: Renovar, 2000.

COUTO, Cláudio Gonçalves; ARANTES, Rogério Bastos. Constituição, Governo e Democracia no Brasil. Revista Brasileira de Ciência Sociais, v. 21, nº 61, 2006.

CRISTI, Renato. Schmitt on Constituent Power and the Monarchical Principle. Constellations, v. 18, $\mathrm{n}^{\circ} 2,2011$.

CUSHMAN, Robert Eugene. Constitutional decisions by a bare majority of the court. Michigan Law Review, v. 19, nº 8, 1921.

DAHL, Robert. How Democratic is the American Constitution? Yale University Press, 2001.

. A democracia e seus críticos. São Paulo: Martins Fontes, 2012.

DANTAS, Ivo. Direito adquirido, emendas constitucionais e controle de constitucionalidade. Rio de Janeiro: Renovar, 2004.

DAWSON, Edward. Adjusting the presumption of constitutionality based on margin of statutory passage. Journal of Constitutional Law, v. 16:1, 2013.

DELLINGER, Walter. The legitimacy of constitutional change: rethinking the amendment process. Harvard Law Review, v. 97, nº 2, 1983.

DENNING, Brannon; VILE, John. The relevance of constitutional amendments: a response to David Strauss. Tulane Law Review, v. 77, 2002.

DEROSIER, Jean-Philippe. The French people's role in amending the Constitution: a French constitutional analysis from a pure legal perspective. In: ALBERT, Richard; CONTIADES, Xenophon; FOTIADOU, Alkmene. The foundations and traditions of constitutional amendment. Oxford: Hart Publishing, 2017.

DIXON, Rosalind. The Supreme Court of Canada, Charter Dialogue, and Deference. Public Law and Legal Theory Working Paper, n 284, 2009.

. Constitutional amendment rules: a comparative perspective. Public Law and Legal Theory Working Paper, $\mathrm{n}^{\mathrm{o}}$ 37, $2011 \mathrm{a}$. 
. Partial Constitutional Amendments. Journal of Constitutional Law, v. 13, 2011 b.

; STONE, Adrienne. Constitutional Amendment and Political Constitutionalism: a Philosophical and Comparative Reflection. Melbourne Legal Studies Research Paper, $\mathrm{n}^{\mathbf{o}}$ 703, 2014.

DOYLE, Oran. Constraints on Constitutional Amendment Powers. In: ALBERT, Richard; CONTIADES, Xenophon; FOTIADOU, Alkmene. The foundations and traditions of constitutional amendment. Oxford: Hart Publishing, 2017.

DWORKIN, Ronald. Response. Boston University Law Review, v. 90:1059, 2010.

. A raposa e o porco-espinho: justiça e valor. São Paulo: Martins Fontes, 2014.

EASTERBROOCK, Frank. Ways of criticizing the Court. Harvard Law Review, v. 95:802, 1982.

EISGRUBER, Christopher L. Democracy and Disagreement: a comment on Jeremy Wadron's Law and Disagreement. N.Y.U. Journal of Legislation and Public Policy, $\mathrm{n}^{\mathrm{o}}$ $6: 35,2002$.

ELKINS, Zachary; GINSBURG, Tom; MELTON, James. The Endurance of National Constitutions. Cambridge University Press, 2009.

ELSTER, Jon. Forces and Mechanisms in the Constitution-Making Process. Duke Law Journal, v. 45, nº 2, 1995.

Don't burn your bridge before you come to it: some ambiguities and complexities of precommitment. Texas Law Review, v. 81, 2003.

EQUADOR. Ley Orgánica de garantías jurisdiccionales y control constitucional de 10 de setembro de 2009. Disponível em: http://www.justicia.gob.ec/wpcontent/uploads/2015/05/LEY-ORGANICA-DE-GARANTIAS-JURISDICCIONALES-YCONTROL-CONSTITUCIONAL.pdf. Acesso em 13/10/17.

ESPANHA. Constitución Española, 1978. Disponível em: https:/www.boe.es/legislacion/documentos/ConstitucionCASTELLANO.pdf.. Acesso em: 20/9/17.

ESTADOS UNIDOS. Constitution of the United States, 1789. Disponível em: https://www.senate.gov/civics/constitution item/constitution.htm. Acesso em: 4/7/17.

ESTLUND, David. Jeremy Waldron on "Law and Disagreement". Philosophical Studies: an International Journal for Philosophy in the Analytic Tradition, v. 99, nº1, 2000.

EUROPEAN COURT OF HUMAN RIGHTS. European Convention on Human Rights. Strasbourg. Disponível em: http://www.echr.coe.int/Documents/Convention_ENG.pdf. Acesso em: 25/7/16. 
EYLON, Yuval; HAREL, Alon. The right to judicial review. Virginia Law Review, ${ }^{\circ}$ 92:5, 2006.

FALCÃO, Joaquim; HARTMANN, Ivar; CHAVES, Vitor. III Relatório Supremo em Números: o Supremo e o tempo. Rio de Janeiro: FGV, 2014.

; ARGUELHES, Diego Werneck. Onze Supremos: todos contra o plenário. In: Onze supremos: o supremo em 2016. FALCÃO, Joaquim; ARGUELHES, Diego Werneck; RECONDO, Felipe. Belo Horizonte: Letramento, Caso do Direito, Supra, Jota, FGV Rio, 2017.

FALLON JR, Richard. The core of an uneasy case for judicial review. Harvard Law Review, v. 121, n 7, 2008.

FEREJOHN, John; LAWRENCE, Sager. Commitment and Constitutionalism. Texas Law Review, v. 81, 2003.

FERRAZ, Anna Candida da Cunha. Notas sobre o controle preventivo de constitucionalidade. Revista de Informação Legislativa, a. 36, nº 142, 1999.

FERRAZ JUNIOR, Tércio Sampaio. Constituinte: Assembleia, Processo, Poder. São Paulo: Revista dos Tribunais, 1985.

FERREIRA FILHO, Manoel Gonçalves. Significação e alcance das "cláusulas pétreas". Revista de Direito Administrativo, v. 202, 1995.

. O poder constituinte. $6^{\text {a }}$ ed. São Paulo: Saraiva, 2014.

FIORAVANTI, Maurizio. Constitución: de la Antiguedad a nuestros días. Madrid: Trotta, 2001.

FREITAS FILHO, Roberto; LIMA, Thalita Morais. Metodologia de Análise de Decisões MAD. Universitas Jus, no 21, 2010.

FRANÇA. Constitution de la République française, 1958. Disponível em: http://www.assemblee-nationale.fr/connaissance/constitution.asp. Acesso em: 10/10/17.

FRANCISCO, José Carlos. Emendas constitucionais e limites flexíveis. Rio de Janeiro: Forense, 2003.

FRIEDMAN, Barry. Dialogue and Judicial Review. Michigan Law Review, v. 91, $\mathrm{n}^{\circ} 4$. 1993.

GARCÍA, Eloy. La sustitución de la constitución en el derecho constitucional colombiano. UNED - Revista de Derecho Político, nº 95, 2016.

GARDBAUM, Stephen. Reassessing the new Commonwealth model of constitutionalism. International Journal of Constitutional Law, v. 8, nº 2, 2010. 
GEE, Graham. The political constitutionalism of JAG Griffith. Legal Studies, v. 28, $\mathrm{n}^{\mathrm{o}} 1$, 2008 .

GEE, Graham; WEBBER, Grégoire. Britain's Political Constitutional: a normative turn, 2009. Disponível em: https://papers.ssrn.com/sol3/papers.cfm?abstract id=1343578. Acesso em: 12/11/16.

2,2010 .

. What is a political constitution? Oxford Journal of Legal Studies, v. $30 \mathrm{n}^{\mathrm{o}}$

GINSBURG, Tom; MELTON, James. Does the constitutional amendment rule matter at all? Amendment cultures and the challenges of measuring amendment difficulty. CoaseSandor Institute for Law \& Economics Working Paper, $\mathrm{n}^{\circ}$ 682, 2014.

GIRALDO, Juan Esteban Jaramillo. La problemática de los limites al poder de reforma de la Constitución Política de 1991. Revista Facultad de Derecho y Ciencias Políticas, v. 43, $\mathrm{n}^{\mathrm{o}} 118,2013$.

GLOPPEN, Siri; WILSON, Bruce; GARGARELLA, Roberto; SKAAR, Elin; KINANDER, Morten. Courts and Power in Latin America and Africa. Palgrave Macmillan, 2010.

GOLDONI, Marco. La dottrina costituzionale di Sieyès. Firenze University Press, 2009.

. Che cos'è il costituzionalismo politico? Diritto e questioni pubbliche, $\mathrm{n}^{\mathrm{o}}$ 10, 2010.

. Two internal critiques of political constitutionalism. International Journal of Constitutional Law, v. 10, $\mathrm{n}^{\circ}$ 4, 2012.

; McCORKINDALE, Christopher. Why we (still) need a revolution. German Law Journal, v. 12, n 12, 2013.

GOODIN, Robert; LIST, Christian. Special Majorities Rationalized. British Journal of Political Science, v. 36, no 2, 2006.

GOUVÊA, Carina Barbosa. As intervenções da ONU no processo de constitution-making nos estados em transição política. Curitiba: Juruá, 2016.

GÖZLER, Kemal. Sur la validité des limites à la révision constitutionnelle déduites de l'esprit de la constitution. Annales de la Faculté de droit d'İstanbul, v. 31, mai 1997. 2008 .

. Judicial Review of Constitutional Amendments: a comparative study. Ekin Press,

GRIFFIN, Stephen. Understanding informal constitutional change. Revista Estudos Institutionais, v. 1, 2015.

GRIFFTH, John. The political constitution. The Modern Law Review, v. 42, ${ }^{\circ}$ 1, 1979. 
GRIMM, Dieter. Comments on the German Constitutional Court's Decision on the Lisbon Treaty. European Constitutional Law Review, nº 5, 2009.

. Constituent power and limits of constitutional amendments. Nomos, $\mathrm{n}^{\mathrm{o}} 2,2016$.

HAMILTON, Alexander; MADISON, James; JAY, John. O Federalista. Brasília: Editora Universidade de Brasília, 1984.

HARTMANN, Ivar Alberto; CHADA, Daniel Magalhães. A razão sem condições de qualidade. In: VILHENA, Oscar (Org.). Coletânea Organizada pela FGV Direito São Paulo com trabalhos que discutem o artigo "A Razão Sem Voto: O Supremo Tribunal Federal e o Governo da Maioria", de Luís Roberto Barroso, 2015. Disponível: http://ssrn.com/abstract=2689294. Acesso em: 5/5/16.

HEINBERG, John Gilbert. Theories of majority rule. The American Political Science Review, 452, 1932.

HENK, Botha. Instituting Public Freedom or Extinguishing Constituent Power? Reflections on South Africa's Constitution-Making Experiment. South African Journal on Human Rights, $\mathrm{n}^{\mathrm{o}}$ 26, 2010.

HIGUERA-JIMÉNEZ, Diego Mauricio. Análisis dinâmico de la línea jurisprudencial respecto de la sustitución de la constitución. Revista Principia Iuris, v. 13, nº 26, 2016.

HOGG, Peter; BUSHELL, Allison. The Charter Dialogue between courts and legislatures. Osgoode Hall Law Journal, v. 35, n. 01, 1997.

HORTA, Raul Machado. Natureza, limitações e tendência da revisão constitucional. Revista de Informação Legislativa, n 121, 1994.

ÍNDIA. Constitution of India, 1949. Disponível em: http://indiacode.nic.in/coiweb/welcome.html. Acesso em: 25/9/17.

. The Constitution (forty-second amendment) act, 1976. Disponível em: http://indiacode.nic.in/coiweb/amend/amend42.htm. Acesso em: 25/9/17.

IRLANDA. Constitution of Ireland, 1937. Disponível em: https://www.taoiseach.gov.ie/DOT/eng/Historical_Information/The Constitution/Constitut ion_of_Ireland___Bunreacht_na_h\%C3\%89ireann.html. Acesso em: 10/9/17.

. Supreme Court of Ireland. Riordan v. An Taoiseach, DJ: 20/5/1999. Disponível em: http://www.bailii.org/ie/cases/IESC/1999/1.html. Acesso em: 21/9/17.

ITÁLIA. Costituzione della Repubblica Italiana, 1948. Disponível em: https://www.senato.it/documenti/repository/.../costituzione.pdf. Acesso em: 18/8/17.

JACOBSOHN, Gary Jeffrey. An unconstitutional constitution? A comparative perspective. International Journal of Constitutional Law, v. 4, n 3, 2006a. 
JACKSON, Vicki. The (mith of un)amendability of the US Constitution and the democratic component of constitutionalism. International Journal of Constitutional Law, v. $13, n^{\circ} 3,2015$.

KAHANA, Tsvi. The notwithstanding mechanism and public discussion: Lessons from the ignored practice of section 33 of the Charter. Canadian Public Administration, v. 44, $\mathrm{n}^{\mathrm{o}} 3$, 2001.

KALYVAS, Andreas. Popular Sovereignty, Democracy, and the Constituent Power. Constellations, v. 12, $\mathrm{n}^{\mathrm{o}} 2,2005$.

KAVANAGH, Aileen. Participation and judicial review: a reply to Jeremy Waldron. Law and Philosophy, n. 22, 2003.

. What's so weak about "weak-form review"? The case of the UK Human Rights Act 1998. International Journal of Constitutional Law, v. 13, nº 4, 2015.

KAY, Richard. Constituent Authority. The American Journal of Comparative Law, $\mathrm{n}^{\circ}$ 59, $\mathrm{n}^{\mathrm{o}} 3,2011$.

KENDALL, Willmoore. John Locke and the doctrine of majority-rule. University of Illinois Press, 1959.

KLEIN, Claude; SAJÓ, András. Constitution-Making: Process and Substance. Oxford Handbooks online, 2012.

KOATZ, Rafael Lorenzo-Fernandez. A exceção que virou regra: a equivocada aplicação do art. 12 da Lei ${ }^{\circ}$ 9.868/1999 e a necessidade de sua releitura. In: SARMENT, Daniel (Coord.). Jurisdição Constituição e Política. Rio de Janeiro: Forense, 2015.

KORNHAUSER, Lewis. Modelando cortes colegiadas. In: BOLONHA, Carlos; BONIZZATO, Luigi; MAIA, Fabiana (Orgs.). Teoria institucional e constitucionalismo contemporâneo. Curitiba: Juruá, 2016.

KOZICKI, Katya. Prefácio à edição brasileira. In: MOUFFE, Chantal. Sobre o político. São Paulo: Martins Fontes, 2015.

; PUGLIESE, William Soares. Uma era de "common law" para o Brasil? In: BUSTAMANTE, Thomas; SAMPAIO, José Adércio Leite; KOKKE, Marcelo; ENRÍQUEZ, Igor de Carvalho. Precedentes judiciais, judicialização da politica e ativismo judicial. Belo Horizonte: Initia Via, 2016.

KRAMER, Larry. The People Themselves: Popular Constitutionalism and Judicial Review. Oxford: University Press, 2004.

KUBLISCKAS, Wellington Márcio. Emendas e mutações constitucionais. São Paulo: Atlas, 2009.

KUMAR, Virendra. Basic structure of the Indian Constitution: doctrine of constitutionally controlled governance. Journal of the Indian Law Institute, v. 49, n 3, 2007. 
KUMM, Mattias. The idea of socratic contestation and the right do justification: the point of rights-bases proportionality review. Law and Ethics of Human Rights, v. 4, nº 2, 2010.

- Constituent Power, cosmopolitan constitutionalism, and post-positivist law. International Journal of Constitutional Law, v. 14, nº 3, 2016.

KYRITSIS, Dimitrios. Representation and Waldron's Objection to Judicial Review. Oxford Journal of Legal Studies, v. 26, nº 4, 2006.

LANDAU, David. Abusive constitutionalism. University of California Davis Law Review, v. 47, 2013.

LEIBHOLZ, Gerhard. The Federal Constitutional Court in Germany and the "Southwest Case". The American Political Science Review, v. 46, nº 3, 1952.

LEVINSON, Sanford. The political implications of amending clauses. Constitutional Commentary, v. 13, 1996.

LIMA, Flávia Danielle Santiago; GOMES NETO, José Mario Wanderley. Poder de agenda e estratégia no STF: uma análise a partir da decisão liminar nos mandados de segurança $\mathbf{n}^{\mathbf{0}}$ 34.070 e $\mathrm{n}^{\mathrm{o}}$ 34.071. In: Constituição e democracia II. MARTINS; Argemiro Cardoso Moreira; NASCIMENTO, Grasiele Augusta Ferreira; RAMOS, Paulo Roberto Barbosa. Florianópolis: CONPEDI, 2016.

; OLIVEIRA, Tassiana Moura de. A judicialização das reformas previdenciárias na jurisprudência do STF: um Tribunal amigo do equilíbrio financeiro e atuarial. Revista de Estudos Empíricos em Direito, v. 4, nº 1, 2017.

; ANDRADE, Louise Dantas de; OLIVEIRA, Tassiana Moura de. Emperor or presidente? Understanding the (almost) unlimited power of the Brazilian Supreme Court's President. Revista Brasileira de Direito, v. 13, nº 1, 2017.

LIJPHART, Arend. Modelos de democracia: desempenho e padrões de governo em 36 países. Rio de Janeiro: Civilização Brasileira, 2008.

LINDAHL, Hans. Constituent Power and Reflexive Identity: towards an ontology of collective selfhood. In: LOUGHLIN, Martin; WALKER, Neil (Ed.). The Paradox of Constitutionalism - Constituent Power and Constitutional Form. United Kingdom: Oxford University Press, 2007.

LIPKIN, Robert Justin. Which Constitution? Who decides? The problem of judicial supremacy and the interbranch solution. Cardozo Law Review, v. 23:3, 2006.

LOCKE, John. Segundo tratado sobre o governo. São Paulo: Abril Cultural, 1978.

LOUGHLIN, Martin. The concept of constituent power. European Journal of Political Theory, v. 13(2), 2014. 
. Constituent power subverted: from English constitutional argument to British constitutional practice. In: LOUGHLIN, Martin; WALKER, Neil (Ed.). The Paradox of Constitutionalism - Constituent Power and Constitutional Form. United Kingdom: Oxford University Press, 2007.

LUNARDI, Soraya Gasparetto. Controle de constitucionalidade na França; vantagens e inovações. Revista Brasileira de Estudos Políticos, nº 103, 2011.

; DIMOULIS, Dimitri. Interpretação conforme a Constituição e a declaração de inconstitucionalidade sem redução de texto. Problemas de aplicação judicial do direito constitucional. Revista Brasileira de Estudos Constitucionais, a.8, nº 29, 2014.

LUTZ, Donald. Toward a Theory of Constitutional Amendment. The American Political Science Review, v. 88, n² 1994.

. Principles of Constitutional Design. Cambridge University Press, 2006.

MADER, George. Binding authority: unamendability in the United States Constitution - a textal and historical analysis. Marquette Law Review, nº 4, v. 99, 2016.

MANCUSO, Wagner Pralon; GOZETTO, Andréia Cristina Oliveira. Lobby: instrumento democrático de representação de interesses? Organicom, v. 14, 2011.

MARBURY, William. The limitations upon the amending power. Harvard Law Review, v. 33, 1919.

MAUERBER JUNIOR, Arnaldo; STRACHMAN, Eduardo. A regra da maioria como agregação de preferências: questões e respostas. Nova Economia, 24 (2), 2014.

MAY, Kenneth. A set of independente necessary and suficiente conditions for simple majority decision. Econometrica, v. 20, nº 4, 1952.

MELO, Marcus André. Mudança Constitucional no Brasil. Novos Estudos, nº 97, 2013.

MENDES, Conrado Hübner. Judicial review of constitutional amendments in the Brazilian Supreme Court. Florida Journal of International Law, v. 17, nº 3, 2005.

2011.

. Direitos fundamentais, separação de poderes e deliberação. São Paulo: Saraiva,

Constitutional Courts and Deliberative Democracy. United Kingdom: Oxford University Press, 2013.

MENDES, Gilmar; VALE, André Rufino do. Questões atuais sobre as medidas cautelares no controle abstrato de constitucionalidade. Observatório da Jurisdição Constitucional, a. $5,2011$.

MENDONÇA, Daniel de. Teorizando o agonismo: crítica a um modelo incompleto. Revista Sociedade e Estado, v. 25, nº 3, 2010. 
MEYER, Emilio Peluso Neder. Decisão e Jurisdição Constitucional. Rio de Janeiro: Lumen Juris, 2017.

MIGUEL, Luis Felipe. Consenso e conflito na democracia contemporânea. São Paulo: Editora Unesp, 2017.

MIRANDA, Jorge; MEDEIROS, Rui. Constituição Portuguesa anotada, Tomo I. Coimbra: Coimbra Editora, 2005. 2007.

. Manual de Direito Constitucional, Tomo II, $6^{\mathrm{a}}$ edição. Coimbra: Coimbra Editora,

MORAIS, Fausto Santos de. Ponderação e arbitrariedade: a inadequada recepção de Alexy pelo STF. Salvador: Juspodivm, 2016.

MORAIS, Laio Correia. O controle de constitucionalidade de emendas constitucionais: como o STF lida com as cláusulas pétreas? Monografia Escola de Formação da Sociedade Brasileira de Direito Público, 2011.

MORESO, José Juan. Disposiciones de reforma constitucional. Doxa, nº 10, 1991.

MOUFFE, Chantal. O regresso do político. Lisboa: Gradiva, 1996.

outubro, 2003.

. Democracia, cidadania e a questão do pluralismo. Política e Sociedade, n. 03, . Por um modelo de agonístico de democracia. Revista Sociologia Política. Curitiba, $\overline{\text { nov. } 2005 .}$

MURPHY, Walter F. Merlin's memory: the past and future imperfect of the once and future polity. In: LEVINSON, Sanford (ed.). Responding to imperfection: the theory and practice of constitutional amendments. Princeton University Press, 1995.

NEGRETTO, Gabriel. Procesos constituyente y refundación democrática. El caso de Chile em perspectiva comparada. Revista de Ciência Política, v. 35, nº 1, 2015.

NEGRI, Antonio. O poder constituinte: ensaios sobre as alternativas da modernidade. Rio de Janeiro: Lamparina, 2015.

NELSON, William. Marbury v. Madison. The Origins and Legacy of Judicial Review. University Press of Kansas, 2000.

NEVES, Marcelo. Do consenso ao dissenso: o Estado democrático de direito a partir e além de Habermas. In: SOUZA, Jessé (Org.). Democracia hoje: novos desafios para a teoria democrática contemporânea. Brasília: UnB, 2001.

NITZAN, Shmuel; PAROUSH, Jacob. Are qualified majority rules special? Public Choice, v. $42, n^{\circ} 3,1984$. 
NOBRE, Marcos. Indeterminação e Estabilidade: os 20 anos da Constituição Federal e as tarefas da pesquisa em direito. Novos Estudos, n $^{\circ}$ 82, 2008.

NORTH, Richard. A Response to Jeremy Waldron's Law and Disagreement. Political Studies Review, v. 1, 2003.

NOVAIS, Jorge Reis. Direitos fundamentais: trunfos contra a maioria. Coimbra: Coimbra, 2006.

NOVAK, Stéphanie. Majority Rule. Philosophy Compass, 9/10, 2014.

O'CONNELL, Rory. Guardians of the Constitution: Unconstitutional Constitutional Norms. Disponível em: https://papers.ssrn.com/sol3/papers.cfm?abstract id=883590. Acesso em: 8/8/17.

O’DONNEL, Guillermo. Accountability horizontal e novas poliarquias. Lua Nova, $\mathrm{n}^{\circ} 44$, 1998.

OFFE, Claus. Political legitimation through majority rule? Social Research, v. 50, $\mathrm{n}^{\mathrm{o}} 4$, 1983.

PEDRA, Adriano Sant'Ana. A Constituição Viva: poder constituinte permanente $e$ cláusulas pétreas na democracia participativa. Rio de Janeiro: Lumen Juris, 2016.

PEREIRA, Paula Pessoa. Supermaioria como regra de decisão na jurisdição constitucional do Supremo Tribunal Federal. Tese (Doutorado em Direito). Universidade Federal do Paraná, Curitiba, 2017.

PERU. Reglamento Normativo del Tribunal Constitucional, 14/9/04. Disponível: http://www.tc.gob.pe/tc/private/adjuntos/institucional/normatividad/reglamentotc.pdf. Acesso em: 14/10/17.

PFERSMANN, Otto. Reformas constituticionales inconstitucionales: una perspectiva normativista. Revista Española de Derecho Constitucional, nº 99, 2013.

POGREBINSCHI, Thamy. Judicialização ou representação? Política, direito e democracia no Brasil. Rio de Janeiro: Elsevier, 2011.

POLETTI, Ronaldo. 1934: Constituições brasileiras, v. 3, Brasília: Senado Federal, 2012.

POLZIN, Monika. Constitutional identity, unconstitutional amendments and the idea of constituent power: the development of the doctrine of constitutional identity in German constitutional law. International Journal of Constitutional Law, v. 14, nº 2, 2016.

PORTUGAL. Constituição de República Portuguesa, 1976. Disponível em: http://www.parlamento.pt/Legislacao/Paginas/ConstituicaoRepublicaPortuguesa.aspx.

Acesso em: 18/8/17.

POST, Robert; SIEGEL, Reva. Roe Rage: Democratic Constitucionalism and Backlash. Harvard Civil Rights-Civil Liberties Law Review, v. 42, 2007. 
PUGLIESE, William Soares. Princípios da Jurisprudência. Belo Horizonte: Arraes, 2017.

QUEIROZ, Otávio de. Dicionário Latim- Português. São Paulo: LEP, 1959.

RAMOS, Elival da Silva. Controle de constitucionalidade no Brasil: perspectivas de evolução. São Paulo: Saraiva, 2010.

. Ativismo judicial: parâmetros dogmáticos. $3^{\mathrm{a}}$ tiragem. São Paulo: Saraiva, 2013.

RANCHORDÁS, Sofia. Constitutional Sunrise. In: ALBERT, Richard; CONTIADES, Xenophon; FOTIADOU, Alkmene. The foundations and traditions of constitutional amendment. Oxford: Hart Publishing, 2017.

REPÚBLICA TCHECA. Constitutional Court Act, 16/6/93. Disponível em: http://www.parliament.am/library/sahmanadrakan\%20dataran/chexia.pdf. Acesso em: $14 / 10 / 17$.

RIGGS, Robert. When every vote counts: 5-4 decisions in the United States Supreme Court, 1900-90. Hofstra Law Review, v. 21, nº 3, 1993.

RODRÍGUEZ, Carlos Amaya. El control constitucional a las reformas constitucionales: el juicio de sustitución constitucional. Revista de Derecho. Escuela de Postgrado, nº 8, 2015.

RODRIGUEZ, José Rodrigo. Como decidem as cortes?: para uma crítica do direito (brasileiro). Rio de Janeiro: FGV, 2013.

ROMÊNIA. Constitution of Romania, 1991. Disponível em: http://www.cdep.ro/pls/dic/site.page?id=371. Acesso em: 10/9/17.

ROSANVALLON, Pierre. Democratic Legitimacy: impartiality, reflexivity, proximity. Princeton University Press, 2011.

ROSENFELD, Michel. A identidade do sujeito constitucional. Belo Horizonte: Mandamentos, 2003.

ROTHENBURG, Walter Claudius. A dialética da democracia: entre legisladores e jurisdição constitucional. In: CLÈVE, Clemerson Merlin; SARLET, Ingo Wolfgang; PAGLIARINI. Direito humanos de democracia. Rio de Janeiro: Forense, 2007.

. Direito Constitucional. São Paulo: Verbatim, 2010.

ROZNAI, Yaniv. Unconstitutional Constitutional Amendments: the limits of amendment powers. Oxford University Press, 2017.

SALDANHA, Nelson. O poder constituinte. São Paulo: Revista dos Tribunais, 1986.

SANTOS, Gustavo Ferreira. Neoconstitucionalismo, Poder Judiciário e Direitos Fundamentais. Curitiba: Juruá, 2011. 
SARLET, Ingo Wolfgang. Os direitos fundamentais sociais como limites materiais ao poder de reforma da Constituição: contributo para uma leitura constitucionalmente adequada. Revista Latino-Americana de Estudos Constitucionais, nº 1, 2003.

SARMENTO, Daniel. Direito adquirido, emenda constitucional, democracia e a Reforma da Previdência. In: TAVARES, Marcelo Leonardo (Coord.). A Reforma da Previdência Social: temas polêmicos e aspectos controvertidos. Rio de Janeiro: Lumen Juris, 2004.

SAUNDERS, Ben. Democracy, Political Equality and Majority Rule. Ethics, v. 121, nº 1 , 2010.

SCHMITT, Carl. Teoría de la Constitución. Madrid: Alianza Editorial, 1996.

SCHWARTZBERG, Melissa. Democracy and Legal Change. Cambridge University Press, 2007.

Counting the many: the origins and limits of supermajority rule. Cambridge University Press, 2014.

SIEYÈS, Emmanuel Joseph. A Constituinte Burguesa. 4a ed. Rio de Janeiro: Lumen Juris, 2001.

SINGH, Mahendra; DEVA, Surya. The constitution of India: symbol of unity in diversity. Yearbook of Public Law, $\mathrm{n}^{\circ}$ 53, 2005.

SILVA, José Afonso. Poder Constituinte e Poder Popular: Estudos sobre a Constituição. $1^{\mathrm{a}}$ edição, $2^{\mathrm{a}}$ tiragem. São Paulo: Malheiros, 2002.

SILVA, Virgílio Afonso da. Ulisses, as sereias e o poder constituinte derivado: sobre a inconstitucionalidade da dupla revisão e da alteração no quórum de $3 / 5$ para aprovação de emendas constitucionais. Revista de Direito Administrativo, nº 226, 2001.

. O STF e o controle de constitucionalidade: deliberação, diálogo e razão pública. $\overline{R e v i s t a}$ de Direito Administrativo, v. 250, 2009.

SHUGERMAN, Jed Handelsman. A six-three rule: reviving consensus and deference on the Supreme Court. Georgia Law Review, v. 37, 2003.

SOUZA, Celina. Regras e Contexto: as reformas da Constituição de 1988. Dados, v. 51, nº 4, 2008.

STELZER, Manfred. Constitutional change in Austria. In: CONTIADES, Xenophon (Ed.). Engineering Constitutional Change: a comparative perspective on Europe, Canada and the USA. Routledge, 2013.

STONE, Adrienne. Putting political constitutionalism in its place?: a reply to Cormac Mac Amhlaigh. International Journal of Constitutional Law, v. 14, nº 1, 2016.

STRAUSS, David. The irrelevance of constitutional amendments. Harvard Law Review, v. 114, 2001. 
STRECK, Lenio Luiz. Jurisdição Constitucional e Decisão Jurídica, $4^{\mathrm{a}}$ ed. São Paulo: Thomson Reuters, 2014.

SUÍÇA. Federal Constitution of the Swiss Confederation, 1999. Disponível em: https://www.admin.ch/ch/e/rs/1/101.en.pdf. Acesso em: 15/9/17.

SUNSTEIN, Cass R. Why societies need dissent. Harvard University Press, 2003.

TAVARES, André Ramos. Justiça Constitucional e suas fundamentais funções. Revista de Informação Legislativa, ano 43, n 171, jul./set. 2006.

TIERNEY, Stephen. 'We the People': Constituent Power and Constitutionalism in Plurinational States. In: LOUGHLIN, Martin; WALKER, Neil (Ed.). The Paradox of Constitutionalism - Constituent Power and Constitutional Form. United Kingdom: Oxford University Press, 2007.

THORNHILL, Chris. Rights and constituent power in the global constitution. International Journal of Law in Context, v. 10, n 3, 2014.

TIMOR-LESTE. Constitution of the Democratic Republic of Timor-Leste, 2002. Disponível em:_timor-leste.gov.tl/wp-content/.../Constitution_RDTL_ENG.pdf. Acesso em 22/8/17.

TOCQUEVILLE, Alexis de. Democracy in America. New York: Barnes \& Noble, 2003.

TOMIO, Fabrício Ricardo de Limas; ROBL FILHO, Ilton Norberto. Accountability e independência judiciais: uma análise da competência do Conselho Nacional de Justiça (CNJ). Revista de Sociologia e Política, v. 21, nº 45, 2013.

TOMKINS, Adam. Our Republican Constitution. Portland: Hart Publishing, 2005.

. The role of the courts in the political constitution. University of Toronto Law Journal, no 60, 2010.

. What's left of the political constitution? German Law Journal, v. 14, n 12, 2013.

TURQUIA. Constitution of the Republic of Turkey, 1982. Disponível em: https://global.tbmm.gov.tr/docs/constitution_en.pdf. Acesso em: 13/0/17.

TUSHNET, Mark. Taking the Constitution away from the Courts. New Jersey: Princeton University Press, 1999.

. Law and prudence in the las of justiciability. The transformation and disappearance of the political question doctrine. North Carolina Law Review, nº 80, 2002.

. Weak-Form Judicial Review and "Core" Civil Liberties. Harvard Civil Rights-Civil Liberties Law Review, v. 41, 2006. 

2009 .

. How different is writing small from writing large. The Good Society, v. 18, $\mathrm{n}^{\mathrm{o}} 1$,

. Democratic founding: We the people and the others - A reply to Hans Agné. International Journal of Constitutional Law, v. 10, n 3, 2012.

. The relation between political constitutionalism and weak-form judicial review. German Law Journal, v. 14, nº 12, 2013.

Peasants with pitchforks, and toilers with Twitter: constitutional revolutions and the constituent power. International Journal of Constitutional Law, v. 13, nº 3, 2015.

UNITED KINGDOM LEGISLATION. Human Rights Act, 1998. Disponível em: http://www.legislation.gov.uk/ukpga/1998/42/contents. Acesso em: 15/3/16.

URBINATI, Nadia. O que torna a representação democrática? Lua Nova, n. 67. São Paulo: 2006.

VEÇOSO, Fabia Fernandes Carvalho; et. al. A pesquisa em direito e as bases eletrônicas de julgados dos tribunais: matrizes de análise e aplicação no Supremo Tribunal Federal e no Superior Tribunal de Justiça. Revista de Estudos Empíricos em Direito, v. 1, nº 1, 2014.

VENEZUELA. Constitución de la República Bolivariana de Venezuela, 1999. Disponível em: http://www.mpptaa.gob.ve/publicaciones/leyes-y-reglamentos/constitucion-de-larepublica-bolivariana-de-venezuela. Acesso em: 9/9/17.

VIEIRA, Oscar Vilhena. A constituição como reserva de justiça. Lua Nova, nº 42, 1997.

VRANES, Erich. German constitutional foundations of, and limitations to, EU integration: a systematic analysis. German Law Journal, v. 14, n 1, 2013.

WALDRON, Jeremy. Law and Disagreement. Oxford University Press, 1999. . A Dignidade da Legislação. São Paulo: Martins Fontes, 2003. 2006a.

.The Core of the Case Against Judicial Review. The Yale Law Journal, 115:1346,

. Disagreement and response. Israel Law Review, v. 39, nº 3, $2006 \mathrm{~b}$.

. A majority in the lifeboat. Boston University Law Review, v. 90: 1043, 2010.

. Five to four: why do bare majorities rule on courts? The Yale Law Journal, 123:1692, 2014.

. Representative Lawmaking. In: WALDRON, Jeremy. Political Political Theory. Harvard University Press, 2016.

. Principles of Legislation. In: WALDRON, Jeremy. Political Political Theory. Harvard University Press, 2016. 
. Judicial review and political legitimacy. Texto da palestra proferida na Corte Constitucional da Colômbia, em 4/8/17.

WALEN, Alec. Judicial review in review: a four-part defense of legal constitutionalism. A review essay on Political Constitutionalism, by Richard Bellamy. Cambridge University Press, 2007. International Journal of Constitutional Law, v. 7, nº 2, 2009.

WALUCHOW, Wil. Constitutions as Living Trees: an idiot defends. Canadian Journal of Law and Jurisprudence, $\mathrm{n}^{\mathrm{o}}$ 18, 2005.

WILLIAMS, Clifton. Expressio unius est exclusion alterius. Marquette Law Review, $\mathrm{n}^{\mathrm{o}}$ 4, v. 15.1931 .

WRIGHT, George R. Could a constitutional amendment be unconstitutional? Loyola University Chicago Law Journal, no 4, v. 22, 1991.

YAP, Po Jen. The conundrum of unconstitutional constitutional amendments. Global constitutionalism, v. 4, $\mathrm{n}^{\mathrm{o}} 1,2015$.

ZELLMER, Sandra; MILLER, Kathleen. The fallacy of judicial supermajority clauses in state constitutions. Disponível em: https://papers.ssrn.com/sol3/papers.cfm?abstract_id=2725234. Acesso em: 2/11/17. 


\section{APÊNDICE A - Procedimentos metodológicos}

Para compor o universo de decisões utilizadas na presente pesquisa, o primeiro recorte metodológico relaciona-se com o tipo de ação objeto de controle de constitucionalidade perante o Supremo Tribunal Federal. Optou-se apenas pelas ações diretas de inconstitucionalidade (art. 102, I, a, da Constituição Federal) que tinham como objetivo o questionamento em torno de emenda constitucional aprovada pelo Congresso Nacional. Isso significa dizer que foram excluídas as ações que se insurgiam contra emenda às constituições estaduais bem como não abrange os mandados de segurança em face de projeto de emenda constitucional. No tocante ao lapso temporal, a pesquisa inclui todo o período constitucional pós 1988 até 31/12/16. Apesar do grande lapso de tempo, a primeira hipótese sugeria que não haveria um grande número dessas ações que impossibilitasse o estudo sobre todas elas individualmente. Tal indicação fora confirmada durante a pesquisa e, por essa razão, possibilitou que o aspecto temporal se mantivesse durante todo o período de vigência da atual Constituição. A primeira medida tomada no sentido da colheita dos dados correspondeu à utilização do portal do Supremo Tribunal Federal na internet (www.stf.jus.br), nessa página acessei o menu "Pesquisa de Jurisprudência" entre os dias 4 e 5 de maio de 2016 e repetido em 4 de março de 2017. Selecionei os termos "emenda", "constitucional" e "adi", por meio do operador booleano “e”. A partir dessa delimitação, foram apresentados 1.369 acórdãos, os quais não foram analisados individualmente em razão do elevado número. Por essa razão, optou-se por delimitar ainda mais os termos da pesquisa com o acréscimo da expressão "congresso nacional". A razão para essa escolha reside no fato de que os primeiros acórdãos apurados tinham como requerido o Congresso Nacional, já que é este órgão o responsável pela promulgação de uma emenda constitucional, nos termos do art. $60, \S 3^{\circ}$ da Constituição Federal. Considerando que o levantamento poderia não estar completo, o segundo passo consistiu na utilização da ferramenta "Solicitação de Pesquisa". Tal como previsto no referido site, essa ferramenta tem como finalidade "auxiliar o usuário em sua pesquisa jurisprudencial, quando não obtenha sucesso em tentativas realizadas na página de pesquisa disponível na internet", por meio de preenchimento de um formulário com as diretrizes para a pesquisa. Encaminhei solicitação com o seguinte teor: "rol de todas as ADI's ajuizadas após a Constituição de 1988 que tiveram como objeto a inconstitucionalidade de Emenda Constitucional até os dias de hoje". Com a resposta, 
realizei a coleta das ações pertinentes à delimitação metodológica proposta, formando, assim, a base de dados exposta na presente pesquisa. Frise-se que algumas ações impugnavam a mesma emenda, mesmo assim, o levantamento as considerou individualmente. Além disso, por se tratar de uma pesquisa ao portal do STF na internet, não é possível a referência a acórdãos não publicados naquela página eletrônica, demais ressalvas sobre a plataforma eletrônica do STF podem ser encontradas no trabalho de Fabia Veçoso e outros (2014). Aos resultados desses levantamentos foram utilizados as seguintes pesquisas como elemento de contraprova: Laio Correia Morais (2011), Alexandre Araújo Costa e Juliano Zaiden Benvindo (2014) e Flávia Danielle Santiago Lima e Tassiana Moura de Oliveira (2017). 
APÊNDICE B - Emendas constitucionais por Título da CF/88

\begin{tabular}{|c|c|c|c|c|c|c|c|c|c|}
\hline T. I & T. II & T. III & T. IV & T. V & T. VI & T. VII & $\begin{array}{l}\text { T. } \\
\text { VIII }\end{array}$ & T. IX & T. X \\
\hline & 4 & 1 & 3 & 18 & 3 & 6 & 11 & 6 & 10 \\
\hline & 16 & 3 & 16 & 19 & 19 & 7 & 14 & 7 & 12 \\
\hline & 20 & 5 & 18 & 20 & 20 & 9 & 19 & 19 & 14 \\
\hline & 23 & 8 & 19 & 41 & 29 & 13 & 20 & 20 & 17 \\
\hline & 28 & 14 & 20 & 77 & 33 & 19 & 29 & 28 & 21 \\
\hline & 45 & 15 & 22 & 82 & 37 & 33 & 36 & 32 & 27 \\
\hline & 52 & 16 & 23 & & 39 & 40 & 41 & 81 & 29 \\
\hline & 53 & 18 & 24 & & 40 & 42 & 42 & & 30 \\
\hline & 54 & 19 & 30 & & 41 & 49 & 47 & & 31 \\
\hline & 72 & 20 & 32 & & 42 & & 48 & & 37 \\
\hline & 90 & 25 & 35 & & 44 & & 51 & & 38 \\
\hline & & 29 & 37 & & 45 & & 53 & & 40 \\
\hline & & 34 & 41 & & 55 & & 59 & & 42 \\
\hline & & 41 & 42 & & 75 & & 63 & & 43 \\
\hline & & 42 & 45 & & 84 & & 65 & & 53 \\
\hline & & 45 & 50 & & 85 & & 66 & & 54 \\
\hline & & 46 & 61 & & 86 & & 71 & & 56 \\
\hline & & 47 & 62 & & 87 & & 85 & & 57 \\
\hline & & 49 & 69 & & & & 86 & & 59 \\
\hline & & 53 & 74 & & & & & & 60 \\
\hline & & 58 & 76 & & & & & & 62 \\
\hline & & 69 & 80 & & & & & & 68 \\
\hline & & 85 & 92 & & & & & & 73 \\
\hline & & 88 & 94 & & & & & & 78 \\
\hline & & & & & & & & & 80 \\
\hline & & & & & & & & & 83 \\
\hline & & & & & & & & & 87 \\
\hline & & & & & & & & & 88 \\
\hline & & & & & & & & & 89 \\
\hline & & & & & & & & & 93 \\
\hline & & & & & & & & & 94 \\
\hline & & & & & & & & & 95 \\
\hline
\end{tabular}




\section{APÊNDICE C - Autores das PEC's convertidas em emenda}

\begin{tabular}{|c|c|c|}
\hline EMENDA No/DATA & PRESIDENTE & LEGISLATIVO \\
\hline $01-31 / 3 / 1992$ & & PEC 5/89 \\
\hline $02-25 / 8 / 1992$ & & PEC 51/90 \\
\hline $03-17 / 3 / 1993$ & & PEC 48/91 \\
\hline $04-14 / 9 / 1993$ & & PEC 45/91 \\
\hline $05-15 / 8 / 1995$ & PEC 4/95 & \\
\hline $06-1508 / 1995$ & PEC 5/95 & \\
\hline $07-15 / 8 / 1995$ & PEC 7/95 & \\
\hline $08-15 / 8 / 1995$ & PEC 3/95 & \\
\hline $09-9 / 11 / 1995$ & PEC 6/95 & \\
\hline $10-4 / 3 / 1996$ & PEC 163/95 & \\
\hline $11-30 / 4 / 1996$ & & PEC 182/94 \\
\hline $12-15 / 8 / 1996$ & & PEC 256/95 \\
\hline $13-21 / 8 / 1996$ & & PEC 48/95 \\
\hline $14-12 / 9 / 1996$ & PEC 233/95 & \\
\hline $15-12 / 9 / 1996$ & & PEC 41/91 \\
\hline $16-4 / 6 / 1997$ & & PEC 1/95 \\
\hline $17-22 / 11 / 1997$ & PEC 449/97 & \\
\hline $18-5 / 2 / 1998$ & PEC 338/96 & \\
\hline 19 - 4/6/1998 & PEC 173/95 & \\
\hline $20-15 / 12 / 1998$ & PEC 33/95 & \\
\hline $21-18 / 3 / 1999$ & & PEC 637/99 \\
\hline $22-18 / 3 / 1999$ & PEC 526/97 & \\
\hline $23-2 / 9 / 1999$ & PEC 626/98 & \\
\hline 24 - 9/12/1999 & & PEC 33/99 \\
\hline $25-14 / 2 / 2000$ & & PEC 627/98 \\
\hline $26-14 / 2 / 2000$ & & PEC 601/98 \\
\hline $27-21 / 3 / 2000$ & PEC 85/99 & \\
\hline $28-25 / 5 / 2000$ & & PEC 07/99 \\
\hline $29-13 / 9 / 2000$ & & PEC 82/95 \\
\hline $30-13 / 9 / 2000$ & & PEC 407/96 \\
\hline $31-14 / 12 / 2000$ & & PEC 249/00 \\
\hline $32-11 / 9 / 2001$ & & PEC 472/97 \\
\hline $33-11 / 12 / 2001$ & PEC 277/00 & \\
\hline $34-13 / 12 / 2001$ & & PEC 308/96 \\
\hline $35-20 / 12 / 2001$ & & PEC 610/98 \\
\hline $36-28 / 5 / 2002$ & & PEC 203/95 \\
\hline $37-12 / 6 / 2002$ & PEC 407/01 & \\
\hline $38-12 / 6 / 2002$ & PEC 289/00 & \\
\hline $39-19 / 12 / 2002$ & & PEC 559/02 \\
\hline $40-29 / 5 / 2003$ & & PEC 53/99 \\
\hline
\end{tabular}




\begin{tabular}{|c|c|c|}
\hline $41-19 / 12 / 2003$ & PEC 40/03 & \\
\hline $42-19 / 12 / 2003$ & PEC 41/03 & \\
\hline $43-15 / 4 / 2004$ & & PEC 254/00 \\
\hline $44-30 / 6 / 2004$ & PEC 228/04 & \\
\hline $45-30 / 12 / 2004$ & & PEC 96/92 \\
\hline $46-5 / 5 / 2005$ & & PEC 575/98 \\
\hline $47-5 / 7 / 2005$ & & PEC 227/04 \\
\hline $48-10 / 8 / 2005$ & & PEC 306/00 \\
\hline $49-8 / 2 / 2006$ & & PEC 199/03 \\
\hline $50-14 / 2 / 2006$ & & PEC $347 / 96$ \\
\hline $51-14 / 2 / 2006$ & & PEC 7/03 \\
\hline $52-8 / 3 / 2006$ & & PEC 548/02 \\
\hline $53-19 / 12 / 2006$ & & PEC 536/97 \\
\hline $54-20 / 9 / 2007$ & & PEC 272/00 \\
\hline $55-20 / 9 / 2007$ & PEC 58/07 & \\
\hline $56-20 / 12 / 2007$ & PEC 50/07 & \\
\hline $57-18 / 12 / 2008$ & & PEC 495/06 \\
\hline $58-23 / 9 / 2009$ & & PEC 336/09 \\
\hline $59-11 / 11 / 2009$ & & PEC 277/08 \\
\hline $60-11 / 11 / 2009$ & & PEC 483/05 \\
\hline $61-11 / 11 / 2009$ & & PEC 324/09 \\
\hline $62-9 / 12 / 2009$ & & PEC 351/09 \\
\hline $63-4 / 2 / 2010$ & & PEC 391/09 \\
\hline $64-4 / 2 / 2010$ & & PEC 47/03 \\
\hline $65-13 / 7 / 2010$ & & PEC 138/03 \\
\hline $66-13 / 7 / 2010$ & & PEC 413/05 \\
\hline $67-22 / 12 / 2010$ & & PEC 507/10 \\
\hline $68-21 / 12 / 2011$ & PEC 61/11 & \\
\hline $69-29 / 03 / 2012$ & & PEC 445/09 \\
\hline $70-29 / 03 / 2012$ & & PEC 270/08 \\
\hline $71-29 / 11 / 2012$ & & PEC 416/05 \\
\hline $72-2 / 4 / 2013$ & & PEC 478/10 \\
\hline $73-6 / 6 / 2013$ & & PEC 544/02 \\
\hline $74-6 / 8 / 2013$ & & PEC 207/12 \\
\hline $75-15 / 10 / 2013$ & & PEC 98/07 \\
\hline $76-28 / 11 / 2013$ & & PEC 349/01 \\
\hline 77 - 11/2/2014 & & PEC 293/13 \\
\hline $78-14 / 5 / 2014$ & & PEC 346/13 \\
\hline $79-27 / 5 / 2014$ & & PEC 111/11 \\
\hline 80 - 4/6/2014 & & PEC 247/13 \\
\hline $81-5 / 6 / 2014$ & & PEC 438/01 \\
\hline $82-16 / 7 / 2014$ & & PEC 55/11 \\
\hline $83-5 / 8 / 2014$ & PEC 103/11 & \\
\hline $84-2 / 12 / 2014$ & & PEC 426/14 \\
\hline $85-26 / 2 / 2015$ & & PEC 290/13 \\
\hline
\end{tabular}




\begin{tabular}{|l|l|l|}
\hline $\mathbf{8 6}-\mathbf{1 7 / 3} / \mathbf{2 0 1 5}$ & & PEC 358/13 \\
\hline $\mathbf{8 7}-\mathbf{1 6} / \mathbf{4} / \mathbf{2 0 1 5}$ & & PEC 197/12 \\
\hline $\mathbf{8 8}-\mathbf{7 / 5} / \mathbf{2 0 1 5}$ & & PEC 457/05 \\
\hline $\mathbf{8 9}-\mathbf{1 5} / \mathbf{9} / \mathbf{2 0 1 5}$ & & PEC 368/09 \\
\hline $\mathbf{9 0}-\mathbf{1 5 / 9} / \mathbf{2 0 1 5}$ & & PEC 90/11 \\
\hline $\mathbf{9 1}-\mathbf{- 1 8} / \mathbf{2} / \mathbf{2 0 1 6}$ & & PEC 182/07 \\
\hline $\mathbf{9 2}-\mathbf{1 2} / \mathbf{7 2 0 1 6}$ & & PEC 11/2015 \\
\hline $\mathbf{9 3}-\mathbf{8} / \mathbf{9} / \mathbf{2 0 1 6}$ & & PEC 4/2015 \\
\hline $\mathbf{9 4}-\mathbf{1 5} / \mathbf{1 2} / \mathbf{2 0 1 6}$ & & PEC 233/2016 \\
\hline $\mathbf{9 5}-\mathbf{1 5} / \mathbf{1 2} / \mathbf{2 0 1 6}$ & PEC 241/2016 & \\
\hline
\end{tabular}


APÊNDICE D - Dados dos julgamentos das ADI's de emenda pelo STF

\begin{tabular}{|c|c|c|c|c|c|c|c|c|c|}
\hline ADI & EMENDA & 1 & 2 & 3 & 4 & 5 & 6 & 7 & 8 \\
\hline 829 & EC 2/92 & & $\mathrm{X}$ & & & & X & & \\
\hline 830 & EC 2/92 & & & $\mathrm{X}$ & & & X & & \\
\hline 833 & EC 2/92 & & $\mathrm{X}$ & & & & $\mathrm{X}$ & & \\
\hline 913 & $\mathrm{EC} \mathrm{3/93}$ & & & $\mathrm{X}$ & & & & $\mathrm{X}$ & \\
\hline 926 & $\mathrm{EC} \mathrm{3/93}$ & $\mathrm{X}$ & & & & & & $\mathrm{X}$ & \\
\hline 939 & $\mathrm{EC} \mathrm{3/93}$ & $\mathrm{X}$ & & & & $\mathrm{X}$ & & & \\
\hline 949 & EC 3/93 & & & $\mathrm{X}$ & & & & $\mathrm{X}$ & \\
\hline 1420 & EC 10/96 & & $\mathrm{X}$ & & & & & $X$ & \\
\hline 1497 & EC 12/96 & & $\mathrm{X}$ & & & & & $\mathrm{X}$ & \\
\hline 1501 & EC 12/96 & & & $\mathrm{X}$ & & & & $X$ & \\
\hline 1749 & EC 14/96 & & $\mathrm{X}$ & & & & & $X$ & \\
\hline 1805 & EC 16/97 & & X & & & & & & $\mathrm{X}$ \\
\hline 1946 & EC 20/98 & X & & & & X & & & \\
\hline 2024 & EC 20/98 & & $\mathrm{X}$ & & & & $X$ & & \\
\hline 2031 & EC 21/99 & $\mathrm{X}$ & & & & $\mathrm{X}$ & & & \\
\hline 2047 & EC $19 / 98$ & & & X & & & & $\mathrm{X}$ & \\
\hline 2096 & EC 15/98 & & & & & & & & X \\
\hline 2135 & EC 19/98 & $\mathrm{X}$ & & & & & & & $\mathrm{X}$ \\
\hline 2159 & EC 19/98 & & & $\mathrm{X}$ & & & & X & \\
\hline 2242 & EC 20/98 & & & $\mathrm{X}$ & & & & $X$ & \\
\hline 2356 & EC 30/00 & $\mathrm{X}$ & & & & & & & $\mathrm{X}$ \\
\hline 2362 & EC 30/00 & $\mathrm{X}$ & & & & & & & $\mathrm{X}$ \\
\hline 2395 & EC 15/98 & & & & & & $\mathrm{X}$ & & \\
\hline 2666 & EC 37/02 & & & & $X$ & & $X$ & & \\
\hline 2673 & EC 37/02 & & & & $X$ & & $X$ & & \\
\hline 2732 & EC 29/00 & & & & $X$ & & X & & \\
\hline 2760 & EC 20/98 & & & & $X$ & & & $X$ & \\
\hline 2883 & EC 20/98 & & & & $\mathrm{X}$ & & & $\mathrm{X}$ & \\
\hline 3099 & EC 41/03 & & & $X$ & & & & $\mathrm{X}$ & \\
\hline 3104 & EC 41/03 & & & & $X$ & & $\mathrm{X}$ & & \\
\hline 3105 & EC 41/03 & & & & X & X & & & \\
\hline 3128 & EC 41/03 & & & & $X$ & $X$ & & & \\
\hline 3133 & EC 41/03 & & & & $X$ & & & & $\mathrm{X}$ \\
\hline 3138 & EC 41/03 & & & & X & & $\mathrm{X}$ & & \\
\hline 3143 & EC 41/03 & & & & $\mathrm{X}$ & & & & $\mathrm{X}$ \\
\hline 3172 & EC 41/03 & & & & $X$ & & & $X$ & \\
\hline 3184 & EC 41/03 & & & & X & & & & $\mathrm{X}$ \\
\hline 3291 & EC 41/03 & & & & $\mathrm{X}$ & & & $X$ & \\
\hline 3297 & EC 41/03 & & & & X & & & & $\mathrm{X}$ \\
\hline 3308 & EC 41/03 & & & & $X$ & & & & $X$ \\
\hline 3363 & EC 41/03 & & & & $X$ & & & & $\mathrm{X}$ \\
\hline
\end{tabular}




\begin{tabular}{|c|c|c|c|c|c|c|c|c|c|}
\hline 3367 & EC 45/04 & & & & $\mathrm{X}$ & & $X$ & & \\
\hline 3395 & EC 45/04 & $X$ & & & & & & & $X$ \\
\hline 3472 & EC 45/04 & $\mathrm{X}$ & & & & & & $\mathrm{X}$ & \\
\hline 3684 & EC 45/04 & $X$ & & & & & & & $\mathrm{X}$ \\
\hline 3685 & EC 52/06 & & & & $\mathrm{X}$ & $\mathrm{X}$ & & & \\
\hline 3686 & EC 52/06 & & & & $\mathrm{X}$ & & & $X$ & \\
\hline 3843 & EC 45/04 & & & $\mathrm{X}$ & & & & $X$ & \\
\hline 3854 & EC 41/03 & $X$ & & & & & & & $\mathrm{X}$ \\
\hline 3855 & EC 41/03 & & & & $\mathrm{X}$ & & & & $\mathrm{X}$ \\
\hline 3867 & EC 41/03 & & & & $\mathrm{X}$ & & & $X$ & \\
\hline 3872 & EC 41/03 & & & & $X$ & & & & $X$ \\
\hline 3998 & EC 41/03 & & & & $\mathrm{X}$ & & & & $\mathrm{X}$ \\
\hline 4014 & EC 41/03 & & & & & & & & $\mathrm{X}$ \\
\hline 4307 & EC 58/09 & $X$ & & & & $\mathrm{X}$ & & & \\
\hline 4357 & EC 62/09 & & & & $\mathrm{X}$ & $X$ & & & \\
\hline 4372 & EC 62/09 & & & & $X$ & & & $\mathrm{X}$ & \\
\hline 4400 & EC 62/09 & & & & $\mathrm{X}$ & & & $\mathrm{X}$ & \\
\hline 4425 & EC 62/09 & & & & $X$ & $X$ & & & \\
\hline 4802 & EC 41/03 & & & & & & & & $\mathrm{X}$ \\
\hline 4803 & EC 41/03 & & & & & & & & $\mathrm{X}$ \\
\hline 4887 & EC 41/03 & & & & $\mathrm{X}$ & & & & $X$ \\
\hline 4888 & EC 41/03 & & & & $\mathrm{X}$ & & & & $\mathrm{X}$ \\
\hline 4889 & EC 20/98 & & & & $\mathrm{X}$ & & & & $\mathrm{X}$ \\
\hline 5017 & EC 73/13 & $\mathrm{X}$ & & & & & & & $\mathrm{X}$ \\
\hline 5296 & EC 74/13 & & $\mathrm{X}$ & & & & & & $\mathrm{X}$ \\
\hline 5316 & EC 88/15 & $X$ & & & & & & & $\mathrm{X}$ \\
\hline 5497 & EC 91/16 & & & & $\mathrm{X}$ & & & & $X$ \\
\hline 5595 & EC 86/15 & & & & & & & & $\mathrm{X}$ \\
\hline 5633 & EC 95/16 & & & & & & & & $X$ \\
\hline
\end{tabular}

Legenda:

1 - Cautelar deferida

2 - Cautelar indeferida

3 - Cautelar prejudicada

4 - Cautelar prejudicada: art. 12, da Lei no 9.868/99

5 - Julgamento procedente do pedido

6 - Julgamento improcedente do pedido

7 - Julgamento sem resolução do mérito

8 - Processo em andamento 